\title{
Highs and Lows of Organizational Decision Making and the Relationship to Collaboration and Technology Tools
}

\author{
Honora M. Rockar \\ Coventry Health Care \\ Pittsburgh, PA, USA \\ hxrockar@cvty.com
}

\author{
Frederick G. Kohun \\ Robert Morris University \\ Pittsburgh, PA, USA \\ kohun@rmu.edu
}

\begin{abstract}
This study examined responses of senior managers drawn from academic, business, military, and non-profit or government organizations during interview sessions. Interview questions covered decision making, organization structure, collaboration, technology tools, and how senior managers helped their employees or organization members solve problems.

The recorded interviews were transcribed and analyzed using NVivo qualitative software. Responses were compared within and across the groups. Individual responses were also compared to the current literature lexicon. Decision making styles were identified and categorized. A unique finding was that all senior managers presented a viewpoint that governed their responses to the interview questions during the interview. The viewpoints were placed into 11 categories and rated by two external raters. The raters tended to place the viewpoints into the same categories as the researchers as well as with each other. In terms of technology tools, these senior managers most often identified databases, calendar and email systems, and video teleconferencing as tools that supported decision making and collaboration.

This study showed that a better understanding by senior managers of decision making methods and collaboration may provide improved decisions and generate the impetus for developing and incorporating true collaborative technology tools.
\end{abstract}

Keywords: Decision Making, Problem Solving, Collaboration, Technology Tools, Organizations

\section{Introduction}

Senior managers within organizations make decisions to deal with problems on a regular basis. In doing so, these senior managers must work with other individuals who are co-located with them or separated from them by distance and time. Whether near or far, problem solving and decision making necessitate the use of technology tools. However, just as a problem solving method

Material published as part of this publication, either on-line or in print, is copyrighted by the Informing Science Institute. Permission to make digital or paper copy of part or all of these works for personal or classroom use is granted without fee provided that the copies are not made or distributed for profit or commercial advantage AND that copies 1) bear this notice in full and 2) give the full citation on the first page. It is permissible to abstract these works so long as credit is given. To copy in all other cases or to republish or to post on a server or to redistribute to lists requires specific permission and payment of a fee. Contact HPublisher@InformingScience.orgH to request redistribution permission. or decision making practice might not be suitable for the unique situation, the technology tools might not be suitable or adequate for the problem at hand and the decision to be made, especially those technology tools claiming to support collaboration.

This paper reviews the research on collaboration in comparison with cooperation, problem solving, decision making, 
and technologies that claim to support these activities. Following the review, we discuss the focus of this paper, which is the notion that senior managers do not have a clear understanding of collaboration and thus lack methods to help their employees or organization members solve problems. The literature review leads to a presentation of the methodology for this qualitative study followed by the results and discussion, including a presentation of the derived organization model and suggestions for future research. As an outline, this paper covers the following topics:

- Review of research on collaboration that defines and compares this term with cooperation;

- Review of research on problem solving, decision making, and technology tools and then compares their relationship to collaboration;

- Illustrates senior managers' understanding of collaboration, problem solving, decision making, and technology tools;

- Presents the research methodology, organization models, and a discussion of the findings and follow-up research question.

\section{Collaboration vis-à-vis Cooperation}

The literature illustrates the difficulty in differentiating between the meanings of collaboration and cooperation. Yet, it is important to make these semantic distinctions to establish a theory of collaboration and enable research investigations to proceed. In fact, Wood and Gray (1991) analyzed nine distinct definitions of collaboration, classified numerous categories, and suggested that "collaboration occurs when a group of autonomous stakeholders of a problem domain engage in an interactive process, using shared rules, norms, and structures to act or decide on issues related to that domain" (p. 146). This classification should encompass all discernible categories and omit any extraneous matters. Therefore according to Wood and Gray, a general theory of collaboration must describe an individual's function who acts to establish, legitimize, and guide the collaborative activity. Thus, collaborative activity maps to three critical issues:

1. Provide preconditions that make collaboration possible and motivate stakeholders,

2. Establish processes that support collaboration, and

3. Enable appropriate outcomes.

These authors felt that rather than focusing on the individual organization, such as, an academic, business, or governmental group, researchers should look at the inter-organization problem domain, believing a general theory of collaboration should start with a classification of the phenomena (Gray, 2000).

Socio-Cultural Perspective. Taking a socio-cultural rather than a problem domain approach, Lin and Beyerlein (2006) pointed out the continued confusion and called for further clarification regarding cooperation and collaboration. As such, Lin and Beyerlein determined that the nature of collaboration was not clearly defined and that related ontological and epistemological concerns were not addressed. Although the notion of collaboration was receiving much attention by organizational researchers and consultants, alike, these experts tended to treat collaboration as a structure, failing to acknowledge its social aspects. Because distinctions among collaboration and cooperation were not consistently recognized, the terms were used interchangeably but meant differently.

Cooperation. Distinguishing cooperation from collaboration, cooperating individuals segment the required tasks and sub-tasks and then undertake those tasks and sub-tasks independently. Assignment and completion of the tasks and sub-tasks occur vertically at a meta-level and at a tasklevel, in other words, a managing individual assigns the task or sub-task to a reporting individual. The reporting individual cooperates and completes the task or sub-task. At agreed-upon mile- 
stones, the individuals bring together their partial deliverables into the final, complete deliverable. Thus, cooperation relates to a predetermined division of labor. From the onset of the assignment, the division of labor is established and made explicit to the individuals at the meta-level and at the task-level. Finally, cooperation is seen as a well-defined process and is more often related to asynchronous (serial) communication due to its vertical, hierarchical structure (Dillenbourg, 1999). And, Axelrod (1984) noted that the underpinning for cooperation is not really trust established by the individuals, but the stability of their associations.

Collaboration. Distinguishing collaboration from cooperation, collaborating individuals perform their tasks and sub-tasks together. However, some spontaneous division of labor can exist when two or more individuals do, in fact, interact and work together. For example, one individual may focus on high-level strategy while the other individual focuses on low-level tasks or sub-tasks (Miyake, 1986). Collaboration does not depend on a predetermined division of labor because members are aligned in their practices, are mutually connected, and negotiate a collective meaning. From the onset, the division of labor is negotiated and agreed upon by the individuals involved. Collaboration requires "a genuine sharing of authority, accountability, resources, and rewards" (Mattessich, 2003, p. 1). In comparison with cooperation, collaboration is seen as a highly interactive process and is more often related to synchronous communication due to its parallel and horizontal structure as well as its self-regulating nature.

Cooperation and Collaboration. Drawing upon the above discussion of cooperation and collaboration and returning to Lin and Beyerlein (2006), these authors identify categorical differences between cooperation and collaboration. For example, Lin and Beyerlein state that cooperation has mixed social interaction, scope, autonomy, and temporality with moderate group and situational dynamics; whereas, collaboration has rich social interaction, broad scope, high autonomy, high group and situational dynamics, along with ongoing temporality. Although cooperation and collaboration are used interchangeably, the terms differ subtly yet greatly in meaning. Because these distinctions are not well understood, the decisions of senior managers may be inappropriate; the actions of organization members may be misunderstood and misdirected; and the technology tools may be inadequate to support the rich, broad, autonomous, dynamic, and ongoing environment of collaboration. Such a mismatched environment may adversely impact members of the organizations, especially senior managers and their groups involved in solving wicked, problems - those problems with no single, right answer or absolute, appropriate solution (Denning, 2009, Rittel \& Webber, 1973).

\section{Problem Solving and Decision Making}

It is important to understand the approaches and processes involved with problem solving and decision making in order to evaluate the impact of collaboration and technology tools on these activities. It is also important to understand how these approaches and processes relate to successful negotiation of decisions and risk management. As we understand the relationships of these principles and practices to problem solving and decision making in organizations, we can provide recommendations and guidance to senior managers regarding techniques and technology tools.

\section{Problem solving}

In general, Hayes (1981) defined a problem as a gap between the existing state and the desired state. To solve a problem, one must represent the problem, plan and decide on a solution, carry out the planned solution, and evaluate the results. Hayes differentiated problems and problem solving by the circumstances under which decisions were made, that is, under the degree of certainty, risk, or conflict. Hayes also defined problem solving as an iterative process in which individuals listed considerations that enabled them to close the gap and solve the problem through 
formal methods and creativity. The problems described by Hayes were simple, having a single solution formed through considerations of managing risk and uncertainty.

Decision Failure. Despite the research conducted in problem solving and decision making for over 50 years, Nutt (2002) believes decisions in organizations often fail. This failure occurs because decision makers jump to conclusions and implement quick solutions. According to Nutt, this need or bias for action causes decision makers to restrict their attention, limit their search, consider few options, and not reflect on the people who are affected by the decision and proposed solution. Such a dysfunctional atmosphere subverts results and prevents the group, as decision makers, as well as the organization from learning from the results and making better decisions in the future.

Organizational Complexity. Organizations have become increasingly complex in terms of products, services, and environments. Whether the organization operates on a global scale, on a national scale, or on a local scale, these organizations must at some level deal with participant ethnic, racial, and gender diversity. This diversity adds to organizational complexity (Witteloostuijn, 1997). In addition to diversity, organizations and their members must deal with the technical complexity that enables them to work together at a distance. Whether that distance is around the globe and across time zones or a few miles apart, the technology is similar but usage rates and familiarity may differ among the participants, making efficient and effective technology usage difficult, time consuming, and often ineffective (Christensen, 2000; Olson, 2005).

Problem Complexity. Another element of organizational complexity is the fact that organizations face increasingly complex problems. Complex problems have many variables, closing the gap between the current state and the desired state becomes more difficult. To deal with these complex issues, organizations pull together multi-disciplinary or cross-functional teams, hire vendors, and off-shore assignments. Thus, these organizationally diverse participants hold different perspectives, knowledge, and approaches to solving problems. To prevent these groups from falling into decision traps, participants must share existing knowledge, state explicit or identify implicit knowledge, and construct new knowledge. To achieve this goal and avoid such traps, participants must identify common ground and negotiate on this basis, which facilitates grounding, information sharing, and knowledge growth across perspectives. Where traditional problem solving and decision making research and methods drew from a single discipline, occurred within one sector, and involved a single individual in making the decision to solve a simple problem, complex problems cross multiple disciplines, involve multiple individuals, and entail multiple perspectives (Beers, Boshuizen, Kirschner, \& Gijselarers, 2006, March, 2002; Parker \& Fischhoff, 2005).

Wicked Problems. In addition to the complex problems that organizations look to solve, organizations now face wicked problems, that is, problems with many variables, societal implications, and no single solution. This notion of wicked problems was originally introduced in the 1960s by Professor Rittel during a lecture presented at the University of California Architecture Department and later defined and solidified in an article (Rittel \& Webber, 1973). Rittel and Webber claimed that confronting social problems through a scientific basis of problem solving and decision making was bound to fail. According to these authors, few modern professionals, including social workers, educators, business executives, and public officials are capable of solving these wicked problems.

The professionalized cognitive and occupational styles that were refined in the first half of this century, based in Newtonian mechanistic physics, are not readily adapted to contemporary conceptions of interacting open systems and to contemporary concerns of equity...The seeming consensus, that might once have allowed distributional problems to be dealt with, is being eroded by the growing 
awareness of the nation's pluralism and of the differentiation of values that accompanies differentiation of publics...A growing sensitivity to the waves of repercussions that ripple through such systemic networks and to the value consequences of those repercussions has generated the recent re-examination of received values and the recent search for national goals. There seems to be a growing realization that a weak strut in the professional's support system lies at the juncture where goal-formulation, problem definition, and equity issues meet. (Rittel \& Webber, 1973, pp. 155-156)

Wicked Problems: Little Information and Diversity. In other words, Rittel and Webber (1973) saw wicked problems as different from simple or complex problems. With simple or complex problems, the individual can formulate a statement that contains the necessary information for understanding and solving the problem; whereas, wicked problems were too devoid of information and diverse in situation. This difference created a dilemma in the planning conducted by experts, the decisions that resulted, and their recommended solutions. In addition, Churchman (1967) asked operations researchers and management scientists the extent to which those researchers and scientists were morally responsible to inform managers of the viability of their recommended solutions to wicked problems. In that wicked problems had no single solution, no stopping rules, and the proposed solution might not solve the problem, Churchman felt these professional experts were obliged to do so.

Wicked Problems and Collaboration. Over the decades, the notion of wicked problems evolved and moved from the proprietary ownership of a single, professional expert who provided a recommended solution to the notion of a collaborative effort (Bell, 2005; Denning, 2009; London, 1995; Roberts, 2000, 2001). In fact, Conklin (2006) draws upon Rittel's notion of wicked problems and extends the notion to a collective intelligence, which is the creativity and resourcefulness groups or teams bring to the problem solving process. The creativity and judgment of the group determines which solution is pursued. Unlike Hayes' iterative problem solving process, Conklin's process is not only iterative but also chaotic. The group might jump from information gathering directly to formulating a solution, jump from solution formation to information analysis, jump from analysis to solution implementation, and then jump back to information gathering. Solving wicked problems requires mastering the chaos and mess that comes with creativity and spontaneity through a coherence of shared understanding and commitment.

Denning's Wicked Problems. Further, Denning (2009) goes on to describe fifteen wicked problems that range from identify theft to health care costs, that is, from technology problems to social problems, Denning believes these problems are all social problems because of the "social consequences of pushing technology beyond its limits; their resolutions lie in the social domain.

Messes cannot be resolved without untangling the social situation" (p. 171). With this statement, Denning (2009) links technology and technology tools to social situations and social problems, that is, wicked problems. Wicked problems require a different paradigm for problem solving and decision making. According to Denning, wicked problems require individuals to identify, learn, question, compare, combine, and lead. Because collaboration is a dynamic and synergistic act of working together (London, 1995; Straus, 2002), collaborators create new and different viewpoints. Collaboration is not consensus. Consensus means to make compromises, which limits possible solutions. Collaboration opens up and expands the discussion to create new possibilities that resolve the wicked problem.

Summary. Comparing the above discussions and definitions of problems and methods of problem solving by Hayes (1981), Nutt (2002), Beers et al. (2006), Rittel and Webber (1973), and Denning (2009) as well as the other authors, a broadening of the definition, complexity, and social significance of the notions are brought to the forefront. This broadening defines the heuristics 
or methods that must be used for solving the problems (Newell \& Simon, 1981), moving from question asking and coordination of tasks to collaboration. The problems described by Hayes are more like the simple problems defined by Denning. The organizational problems described by Nutt and Beers are more like the complex problems described by Denning, and the wicked problems of Rittel compare to the wicked, messy problems described by Denning. The wicked problems defined by both Rittel and Webber as well as Denning describe social situations that require specialized skills, creative and collaborative ways of working, and suitable supporting technology tools when it comes to solving problems and making decisions.

\section{Decision making}

Decision processes take place at varying points during problem solving. As the viewpoints of researchers in problem solving evolved over time, the viewpoints of decision researchers evolved as well. This evolution occurred from the classical notions of decision making, which were normative and analytical. The classical notions of decision making drew upon political, economic, risk, and game theory models (Fischhoff, Lichtenstein, Slovic, Derby, \& Keeney, 1993; Rappoport \& Wallsten, 1972; Simon, 1959; Yates, 1989). Included in this evolution are the social and behavioral models of decision making, the natural decision making models, as well as the team and organizational models of decision making. Aspects of behavioral, natural, and organizational decision making are discussed below in relation to solving problems.

Behavioral Decision Making. As Denning (2007, 2009) and Denning and Yaholkovsky (2008) question problem solving dimensions, Einhorn and Hogarth (1981) question the economic, statistical, and management science descriptions of decision making. Thus, Einhorn and Hogarth place decision making processes within a psychological context and emphasize the importance of cognitive representation, identifying conflicting issues, and learning from experience. Einhorn and Hogarth note the inter-relationships and dependencies of these elements for complex decision making and state that these elements are often not considered in decision making research due to the focus on making judgments, eliminating biases, and selecting choices. Thus, vital, problem solving and concept formation are often left out of the equation.

Group and Distributed Decision Making. Fischhoff and Johnson (2002) expand the notion of individual and centralized decision making to group and distributed decision making. In other words, information and authorization for making decisions are considered distributed within and across groups that are geographically dispersed, for example, multinational corporations, diplomatic agencies, and government organizations. According to these authors, simple solutions derived from previous research seem not to work. Some of those suggested solutions were to increase the stakes on performance, illustrate previous problems and tasks, or provide statistical information on decision theory. When it comes to distributed decision making, the requirements are far different. When working with a broad, diverse range of individuals over distances, differences in terminologies, shared experiences, and the ability to communicate and coordinate actions affects the decision making process. The complexity of the decision process means that a solution applied in one area might cause a problem to arise in another area.

Decision Points. Other researchers (Radner, 2002; Saaty, 2008; Simon, 1997) investigate how individuals and groups decide to make their decisions and the elements that bind those decision points. Those decision points could be determined by a delta point in terms of costs, probability, or access to new information. Calling upon previous work, Radner as well as Zandt (Radner, 1992; Radner \& Zandt, 1992) extend these issues to information processing in organizations. In doing so, they compare the architecture, network, and hierarchy of the organization to its decision making capabilities. For Radner and Zandt, the architecture of information processing is different from the architecture of decision making. The networks of efficient information processing do not map to traditional, hierarchical organization charts. "Different decisions, or different groups of 
decisions, will utilize different networks for information processing. Although different decisions will be based on different information, those information sets are likely to overlap in many cases" (Radner, 2002, p. 344). The relationships of problem solving and decision making to information access and processing hold true for individuals, groups, and organizations.

Cognitive Psychological Approach. Taking an alternative individual and cognitive psychological approach to decision making, and then, applying those areas to organizational decision making, Payne (2002) notes that Simon's bounded rationality depicts an individual's cognitive capabilities and economic needs in making decisions. Those limits can also apply to organizational decision making in that individuals, as managers or within groups, are making those decisions. However, Payne adds a cognitive approach to the limits and an individual's information processing abilities. These limits are bounded by attention levels, preferences, memory, and processing capacities. In that individuals make up organizations, these limits also apply to organizations. Individuals function within organizations according to the structure, operational styles, and reward systems; therefore, it is not unreasonable to think that preferences based on these elements influence how individuals think about problems and make decisions.

Naturalistic Decision Making. Moving from experimental research on individual decision making to a practice that attempts to understand decision making in its social and technical contexts, Naturalistic Decision Making (NDM) researchers (Klein \& Hoffman, 2008; Schraagen, Klein, \& Hoffman, 2008; Schraagen, Militello, Ormerod, \& Lipshitz, 2008; Sterman \& Sweeney, 2005; Zsambok \& Klein, 1997) explore the domain of practitioners as they make decisions in real-world settings with an emphasis on their cognitive functions. With its roots in anthropology, linguistics, and cognitive sciences, Naturalistic Decision Making research assumes two perspectives. These perspectives are a micro-cognitive viewpoint and a macro-cognitive viewpoint. The microcognitive perspective examines memory and problem solving. The macro-cognitive perspective examines decision making, sense making, planning, adaptation, problem detection, and coordination of activities. Whether a micro-cognitive or macro-cognitive perspective, these researchers implement protocols that examine subject matter experts as they make decisions in their typical day and under difficult conditions. NDM researchers do not view their subject matter experts as infallible; rather, their subjects' fallibilities provide insights for recommendations and improving decision making.

Naturalistic Decision Making and Mental Models. The characteristics of NDM settings provide an examination of ill-structured problems, uncertain dynamic environments, shifting and competing goals, time-stressed activities, high stakes, multiple players, as well as organizational goals and norms. The settings include individuals, teams, organizations, and systems that coordinate people with technology. Some NDM researchers attempt to identify mental models, which are a phenomenon or presentation of consciousness. These mental models emerge from the interworkings of an individual's perception, comprehension, and organizational knowledge. Mental models are shaped by regularities and are mappings of the environment. Mental models are representational and are derived from the descriptive language of the subject matter experts through a form of Cognitive Task Analysis (CTA). This method follows defined procedures and specific protocols to solicit the working knowledge, processes, and decision points of the experts (Klein \& Hoffman, 2008).

Natural Decision Making and Cultural Variation. Some NDM researchers examine cultural variations in mental models and decision making. Often individuals are drawn from various nations because of their diverse knowledge and perspectives. This diversity is expected to create a dynamic, leading to innovative solutions. However, these cultural differences often create varying perspectives and differing positions that stifle decision making. These diverse individuals need to be sensitive to the cultural differences. Other NDM researchers examine not only cultural differences but the differences that occur within teams, groups, and collaborative decision making. 
These researchers identified three key variables to create cohesion among diverse individuals. The variables are unity, trust, and respect. Unity indicates the degree of oneness the individuals feel with the group. Trust indicates the sense of confidence the individuals have within the group. Respect means upholding each individual's sense of honor and dignity within the group. While these variables are important, the element of the decision point is also important. Varying cultures differ not only in their perspectives, but also the point or place where decisions are made (McHugh, Smith, \& Sieck, 2008).

Natural Decision Making and Social Context. Naturalistic Decision Making researchers take into account the social and contextual environments for decision making. These researchers examine the language used, scenarios described, and tasks performed by the participants, establishing mental models. Noting cultural variations, NDM researchers identify the elements that prevent diverse individuals from working together in a creative and innovative way. NDM researchers attempt to make recommendations for improving decision making for individuals, teams, and groups.

Teams, Groups, and Organizational Decision Making. When examining decision making, some researchers focus on teams and small groups. These teams may be involved in new product development or coordinating strategic initiatives. Whether or not the teams follow an approved charter with defined goals, decisions are made. The team design, structure, and methodology are of interest to those researchers investigating team decision making skills (Beyerlein \& Johnson, 1994; Cannon-Bowers, Solas, \& Converse, 1993, Michie, Dooley, \& Fryxell, 2007; Schrage, 1989). Schrage questions the value of teams, stating their creation leads to political posturing as opposed to value creation. Differentiating teamwork from collaboration, Schrage states that teams are formal entities with a distinct structure and assigned goals. Whereas, collaboration is dynamic and those involved develop the goals (Schrage, p. 3). Beyerlein examines self-managing work teams and questions the adoption of new practices without the consideration to costs or risks. While self-managing work teams establish their own goals, the underlying fact is that selfinterests are involved. If one succeeds, others must fail. Although self-managing and goal setting, these teams are not collaborative groups (Beyerlein, p. 124). When it comes to top management teams that work for strategic objectives, Michie speaks to goal consensus and information diversity for successful decision making on the part of top management teams. These teams must moderate and mediate their goal definitions. Michie states that "on-going interaction of conflicting information within a shared frame of interpretations, if successful, will promote collaboration" (Michie, p. 130). Again, assigned teams, goal setting, and collaboration are commingled. This discussion demonstrates the lack of understanding about collaborative dynamics in relation to consensus building.

New Organization Theory. Moving to an organizational context for decision making, aspects of Naturalistic Decision Making combine and create New Organization Theory (NOT). This theory contains five major streams or positions: resource dependence, transaction-cost economics, organizational ecology, institutional theory, and network approaches. Where NDM describes the activities undertaken by individuals as they attempt to make decisions in a real-world context, NOT attempts to describe the issues and complexities individuals must overcome when purposefully making decisions in an organizational context (Connolly \& Koput, 1997). The reliance on organization members as human resources, the internal and external exchanges made to obtain the necessary material goods, the social setting and environment, its norms, and social relationships are thought of as sources of information and knowledge.

Individual Context Decision Making. Initially, research on decision making in organizations applied the notions of individual rational actors and the selection of preferences to organizational decision making processes. Current day researchers view organizational decision making through the lens of situations and settings in which individuals act separately or in concert according to 
their ability for making sense of complicated situations, for determining the consequences or appropriateness of their actions, for creating meaning, and for the understanding that past actions and past results do not necessarily define optimal decisions for today, whether making decisions on individual task assignments, department safety procedures, divisional cost containment, or organizational strategic agendas (Dutton, 2002; March, 2002).

Negotiation Principles and Practices. Within the voluminous research and literature on problem solving and decision making, the researchers and writers have little mention for negotiation as part of decision making. Yet individuals must negotiate internally when making decisions alone and negotiate externally when in concert with others. Whether at the senior management or lower levels within organizations, members handle decisions that involve not only business but moral and ethical issues. These issues cannot be easily resolved because of diversity in the organization or its external environment. The complexities of these decisions are made more evident by the changing norms and values of a pluralistic organizational environment. Therefore, individual and collective deliberations are required to adequately make decisions and solve problems. Perhaps, the areas most overlooked in research on problem solving and decision making are the methods and skills involved with deliberation and negotiation.

Negotiation, Mediation, Problem Solving, and Facilitation. Straus (1993) states a difference exists between negotiation, mediation, problem solving, and facilitation. Negotiation often implies negative situations, requiring third-party mediation. Mediation often relies on caucusing with separate parties. Problem solving often involves conflict and requires third-party facilitation. Facilitation operates with all stakeholders meeting face-to-face. According to Straus, our society makes decisions on either a win-lose approach or a consensus-based win-win approach. Neither of which are very effective. In addition, Straus feels our linear approach to problem solving is ineffective. This linear approach identifies key stakeholders, establishes key issues, and then implements solutions. An alternative approach is more dynamic, moving back and forth between formal and informal structures of decision making. This alternative approach requires negotiation skills for consensus building and collaboration. Boven and Thompson (2003) see negotiation as part of problem solving process rather than as part of a decision making analysis. The mental models of negotiators influence their behavior and their outcomes. No matter how negotiation is viewed, it can be seen as an element of problem solving and decision making that needs to be included in collaborative decision making methods and technology tools.

\section{Technology Tools}

Members collaborate to learn, share identity, commune, and communicate with others to identify and solve problems and make decisions. Collaborative activities are chaotic, dynamic, and involve rich social interaction over a broad scope or range of topics requiring high autonomy and ongoing temporality. For successful intra and inter-organizational problem solving and decision making, members must establish trusting relationships, create common purpose, share governance, and enable collaboration. Members must also have a clear understanding of their roles and responsibilities for problem solving and decision making to function effectively. And, problem solvers and decision makers must have adequate technology tools to support their activities, especially during virtual operations.

According to Chituc et al. (2009), the advances in decision support systems, information and communication technologies, and economic factors prompt organizations to employ new and unique methods of collaboration, such as collaborative networks or electronic networks of practice. These collaborations necessitate applicable architecture frameworks, appropriate application tools, adequate systems, and pertinent platforms in order to interoperate and support heterogeneous and geographically distributed intra and inter-organizational activities. A conceptual frame- 
work for seamless interoperability in a collaborative networked environment requires the following six elements:

1. Messaging services;

2. Collaboration profile/agreement definition and management service;

3. Clusters of collaborative activities;

4. Centralized repositories;

5. Business document sets and contracting document sets;

6. Performance assessment service (Chituc, et al., 2009, p. 317).

While the above components, classifications, and elements provide the basic structural requirements for collaborative networked environments, the applications that claim to be collaborative tools are wide and varied, ranging from email applications; calendaring and scheduling tools; instant messaging (IM); teleconferencing, web-conferencing, video teleconferencing (VTC); online document repositories; online discussion sites; knowledge bases or wikis; realtime, web-based, pushed information distribution or really simple syndication (RSS) feeds; and automatically assembled, web-based, pulled information or mashups. These applications are, in fact, basic information communication technologies rather than collaboration tools. This position is based on the derived definition of collaboration where a dynamic community works together to identify and solve problems (Brown \& Duguid, 1991; London, 1995; Rittel \& Webber, 1973). The requirements for collaboration tools must include those elements of problem identification, negotiation, and solution generation.

Some of these elements can be found in such applications as Hermes, Sibyl, or Zeno, which claim to be computer supported argumentation and collaborative decision making systems (Gordon \& Karacapilidis, 1997; Karacapilidis \& Papadias, 2001; Lee, 1990). These systems established the foundation for further expansion to the World Wide Argument Web (Rahwan, Zablith, \& Reed, 2007) that combined the argumentation theories of Perelman and Olbrechts-Tyteca (1997) and Toulmin (1980) as well as Government to Government (G2G) web applications (Karacapilidis, Loukis, \& Dimopoulos, 2004) and multi-agent and mixed-initiative collaborative decision making systems (Ernst, 2009; Ferguson \& Allen, 2007; Panzarasa, Jennings, \& Norman, 2002) for distributed asynchronous or synchronous collaborative activities. These argumentation properties were meant to facilitate problem and solution negotiations among collaborative groups. However, these collaborative, decision support, and argumentative technology tools as well as the information communication technology tools lack capabilities to enable collaborative groups to identify those problems that require their immediate and greatest attention. Lacking the ability to coordinate and consolidate problem areas, collaborative working groups may miss valuable problem identification and solution opportunities. Thus, lacking adequate decision techniques and supporting technologies, senior managers may be unable to provide the necessary assistance to help their members make decisions and solve problems.

\section{Methodology}

Analysis of qualitative investigations attempt to identify patterns and provide explanations. The analyses are formed through induction or deduction. This study implemented an inductive approach, incorporating explicit methods to manage and organize the data. The methodology included noting terms, topics, and schemas that defined themes. The method also included grouping categorical results to derive connections and re-organizing the results to derive comparisons. The purpose of the analysis was not to report on the kinds of decisions made but how senior managers supported and facilitated problem solving, especially wicked problems, as well as collaboration within the organization. 
Study Overview. This study was performed by interviewing senior managers to identify their perceptions of how they helped employees solve problems. In addition, an examination was made of senior managers' conceptions of collaborative and cooperative work within their organizations, and the possible relationships of these activities to technology tools to enable groups in identifying and solving ill-defined problems. The data were obtained in one-time, face-to-face or phone interviews with senior managers. The interviews were descriptive accounts of the managers' perceptions of how they helped employees solve problems. Established by follow-up probe questions, secondary topics covered in the interviews were the organization's culture, business model, procedures, and processes. An initial analysis of the data was conducted to identify the specific thematic components as stated by the senior managers in relation to problem solving, decision making, and collaborative and cooperative work.

Viewpoints. An unexpected result of this initial analysis was the point of view participants assumed during the interview. These interview viewpoints depicted the participant's focus or frame regarding the organization and its members. A label was created for each identified viewpoint to succinctly describe or summarize the focus or point of view. A second analysis examined the terms used by the managers. Comparisons were made of these terms against terms initially derived from the research literature and considerations were made during the analysis regarding the participant's organization. A third analysis was conducted via an in-depth coding of four randomly selected participant interviews (Participant 101, Academic; Participant 107, Business; Participant, 116 Military; and Participant 118, Non-Profit or Government). These four randomly selected interviews were also reviewed by two co-raters for comparison with that of the primary researcher.

Participant Selection. The initial participant selection was drawn from a convenience sample of senior managers or comparable counterparts in the Pittsburgh area identified through personal contacts, providing a snowball sampling. The resulting sample expanded and also included participants from outside the Pittsburgh area. Each manager was contacted personally by phone or email to request a face-to-face or phone interview. The participants were drawn from four organization types: academic, corporate, military, and non-profit service or government organization. An attempt was made to have at least 4 participants selected from each type, totaling 16 participants. But, the sample expanded with 20 participants interviewed. The total sample included 4 academic participants, 6 business participants, 6 military participants, and 4 non-profit service or government participants. Out of the 20 participants interviewed, 16 were men and 4 were women, ranging in age from 45 to 58 years and between 5 to 20 years experience with their respective organizations. While titles were identified, salary and educational levels were not.

Interview Protocol. Individual interviews and data collection were conducted at the office of each senior manager participating in the study or at a mutually agreed upon location conducive to conducting an undisturbed interview or over the phone at an agreed upon time. The senior managers were interviewed for between 45 to 90 minutes using a prepared interview protocol, consisting of an open-ended question and then probing their responses with follow-up questions. However, the order presented for the primary question and follow-up probe questions varied depending upon the ease with which the participant engaged in the interview. Before each interview began, an informed consent statement was read aloud and verbal consent was obtained from each participant. During each interview, hand-written notes were taken. The verbalized consent and the audio of the interview were digitally recorded. The 20 interview transcriptions totaled approximately 300 double-spaced pages with 6,000 lines of text.

Participant Perception. The interviews aimed at eliciting the participants' perceptions of their personal assistance in problem solving, perceptions of problem solving within their organization as well as ways of working. For example, questions were asked regarding an organization's guiding principles; practices and rewards; processes, procedures, tasks, and tools; operating presence 
and place. Each participant's responses were compared in relation to their organization type both paradigmatically and syntagmatically (D'Angelo, 1975). Most often, the conversation flowed from an initial question, "From your perspective, how do you help your employees solve problems?" then expanded the discussion with the follow-up probe questions. The primary question and follow-up probe questions were not stated in any consistent presentation to avoid leading or limiting the conversation. Because "Being an analyst means using common sense and making choices about when and what bits of data to ask questions about" (Corbin \& Strauss, 2008, p. 71), real-time determinations were made of how to phrase the primary question and follow-up probe questions in order to capture data that could be coded into categories. Therefore, "any models produced will have arisen out of a close reading of the data and thus will be closely supported by the data. They are, in that sense, data-driven" (Gibbs, 2007, p. 86), and so close alignment with the categories was maintained.

Saturation. Although it is not unusual for a researcher to have new insights during data collection, it is important to remain focused. Therefore, data were collected until saturation occurred. That is, "the development of categories in terms of their properties and dimensions, including variation, and possible relationships to other concepts" (Corbin \& Strauss, 2008, p. 148) had occurred. The researchers arrived at an intuitive insight as to when the interview responses were becoming repetitive in relation to the initial question as well as the variations of what was said and what was not said in the interviews that tended to confirm, reaffirm, or disaffirm patterns. Thus, the researchers determined data saturation occurred when all organization types had four or more participants interviewed and the additional interviews provided no, unique insights. Therefore, the researchers ended data collection with the 20th participant.

Coding. For data analysis, axial coding and open coding methods were implemented as well as comparative analysis and conceptual saturation. Axial coding establishes a process to cut across or relate concepts to each other; open coding sets up a method to segregate and delineate data, yet qualify the concepts in terms of their properties and dimensions. Comparative analysis compares incident to incident, that is, case to case. This analysis draws out similarities and differences. Finally, conceptual saturation facilitates the determination of when sufficient data has been obtained to account for the concept in terms of properties and dimensions to account for the variation (Corbin \& Strauss, 2008).

Transcription. The audio recordings taken during the interviews were transcribed. The transcriptions were inserted into the NVivo application, which is a respected software tool for qualitative data analysis. Once the transcriptions were inserted, the NVivo software was set up to facilitate analysis of the data. This tool enabled a deeper understanding and more flexible analysis of the data. Using NVivo, the transcriptions were axial and open coded according to a coding scheme derived from the organization types and elements that emerged from the data. This method allowed for a paradigmatic and syntagmatic analysis of the data. That is, the various responses from those in the academic, business, military, non-profit service or government organizations could be compared within and across these groups. Three rounds of coding were undertaken. The first round analyzed the responses from the primary question and follow-up probe questions. During the second round of coding, queries were created and run using the NVivo application. These queries enabled the identification of terms and phrases within the transcripts for comparison against those terms and phrases identified within the research literature. For the third round of coding, 4 randomly selected participant interviews were hand coded. These 4 participant interviews were also reviewed and coded by 2 co-raters for comparison.

First Coding Round. Any discussions of problem solving, decision making, and negotiation were noted and compared to elements of the decision making theory to further understand the procedures, processes, and technologies used for problem identification, definition, and solution creation within organizations (Beers et al., 2006; Espinosa \& Harnden, 2007; Franco \& Mead- 
ows, 2007; Jones \& Roelofsma, 2000; Morton, Ackermann, \& Belton, 2007; Mueller, Mone, \& Barker, 2007). To facilitate analysis of data relating to this theoretical position and collaboration, the data was segmented into the notions of problem identification methods, problem solving methods, and decision making methods.

Discussions of presence and place (Cottone, Pieti, Schivinato, Soru, Martinelli, Varotto, \& Mantovani, 2009; Jackson, Gharavi, \& Klobas, 2006) were also noted and compared to elements of synchronicity, that is, the effectiveness of asynchronous (serial) individual activities versus synchronous (parallel) collaborative activities (DeLuca \& Valacich, 2006) as well as the adequacies of supporting technologies (Jackson et al., 2006; Karsten, 1999a, 1999b; Weill \& Aral, 2006). And, discussions of the organization's culture were noted and compared to the approaches of open systems, learning systems, aligned systems, or on a continuum from a controlling to collaborative organizational environment (Fleet \& Griffin, 2006; Halbesleben, Wheeler, \& Buckley, 2006). The data were also segmented into the notions of location, time, environment, and technology to enable a more in-depth analysis and elaboration of the organizational environment. This segmentation translated into the virtual or co-located, time, environment, and technology component descriptions.

Second Coding Round. Further extending the analysis, specific terms and phrases were identified within the individual interview transcripts and compared to terms and phrases identified within the applicable research literature. These specific terms and phrases were derived from the reviewed research literature and, therefore, compared the language used in specific research domains with the language used by those interviewed. This method provided a comparative analysis of linguistic and discourse cues that occurred throughout the interviews (D'Angelo, 1975). The discourse cues enabled a more detailed and varied analysis of the interview transcripts provided within the results.

Third Coding Round. The third round of coding covered the 4 randomly selected participant interviews. The random selection picked Participant 101 for Academic, Participant 107 for Business, Participant 116 for Military, and Participant 118 for Non-Profit Service or Government organization. These 4 transcripts comprised a 20\% sample of the data. Reliability of the coded data was determined by the 2 additional co-raters with an inter-rater reliability coefficient of .78. Each rater coded the same transcriptions as the primary researcher. The ratings were compared to each other as well as to those of the researchers' ratings. In addition to coding the transcripts, the raters were also asked to select from a list of interview participant viewpoints. Eleven interview viewpoint categories were identified from the 20 participants' interview transcripts in which they presented a particular viewpoint or focus. The researchers provided succinct labels for each participant viewpoint, for example, Chain of Command or Skilled Manager. The raters were to make three passes through the interview transcripts.

Discrepancies. There can be discrepancies between what senior managers espouse and their actions. These discrepancies have been identified as Espoused Theories and Theories-In-Use. Espoused Theories are defined as personal accounts of actions. Theories-In-Use are defined as observed accounts of behaviors. In their self-descriptions, managers were found to have significant discrepancies between what they said and what they did. While managers' self-reports talked about being open-minded, transparent, and cooperative, their observed actions were identified as closed-minded, ambiguous, and controlling. It was felt that these reports were used for selfprotection, particularly when managers were dealing with situations that might threaten their position or embarrass them personally. These theories enabled the development of two models. One model illustrated the negatives depicted by the theories. The other model illustrated methods for overcoming those negatives so that managers could improve their own performance. These theories and models, derived from exploration and observation of senior managers, provide a cautionary tale (Argyris \& Schön, 1996). With this caveat in mind, this study compared the data in order 
define an organization model according to movement along a continuum for each of the categories by comparing the responses of the individuals within and across the groups.

Summary. From the first coding, this study reviewed senior managers' notions of problem solving, decision making, and organization culture, structure, and practices. These notions were derived from the senior managers' responses to the primary question and follow-up probe questions. The perceptions of senior managers' were drawn from what was said as well as what was not said. The responses of how senior managers helped employees solve problems, how they described the work processes, and how they described the environment provided insights into the senior managers' perceptions and mental models of their organizations.

From the second coding, this study compared the linguistic concepts taken from the research literature regarding problem solving, decision making, organization theory, and technology tools and compared those concepts to the language and references presented by the senior managers. This conceptual analysis illustrated the depth to which each of these research genres infiltrated professional practice as tacit knowledge. The third coding compared the analysis of the researchers to the analyses of external raters. This procedure provided support for the identified notion of interview viewpoints. These interview viewpoints depicted senior managers' particular viewpoints, focuses, or perspectives regarding their employees or members and their organizations. In addition, this procedure provided support for the researchers' word and phrase selections, comparing the coding of the randomly selected participant interviews with those of the raters.

From these analyses, this study evaluated the perceptions of senior managers with regard to problem identification methods, problem solving processes, decision making techniques, and environments, deriving the components of a subsequent organization model. The study also determined the extent to which senior managers apprehended the differences between collaborative and cooperative activities, and the identified the degrees to which senior managers considered technology tools, their implementation, usage, and future requirements. Finally for future theory development and research, we presented a discussion of whether or not senior managers actually help employees in their collaborative problem solving and decision making processes within organizations for successfully identifying, analyzing, and solving complex, wicked problems.

\section{Results}

As previously stated, an unexpected result of this study was the singular viewpoint that each participant assumed during the interview process. These viewpoints structured and framed the responses of the participants. The viewpoints came to illustrate not only the participants' relationships to their organizations but also their problem solving and decision making approaches as well as their perceptions of members, external stakeholders, and competitors.

From the responses of the 20 participants, 11 interview viewpoints were identified and labeled. The labels assigned to the interview viewpoints were derived from specific, meaningful words or phrases used by each participant throughout the interview. The participant viewpoint identified most often was that of Organizational Change with 5 participants assigned the label. This label was identified from the participants' repeated statements regarding how their organizations were undergoing change or how they, themselves, were instituting change. Labels for the other interview viewpoints were similarly identified and assigned. These viewpoints were as follows: Chain of Command, Family Oriented Service, Multi-Facetted Organization, Partnership, Policy Implementation, Skilled Manager, Ultimate Decision Maker, Unencumbered Innovation, Voice of the Customer, and World Class Combatant Power.

Additionally from the responses of the 20 participants, their problem solving and decision approaches were identified, labeled, and compared to their viewpoints. The approaches created 4 categories as follows: 
1. Group Problem Solving and Individual Decision Making,

2. Group Problem Solving and Group Decision Making,

3. Individual Problem Solving and Individual Decision Making, and

4. Decision Implementation.

The interview viewpoints as well as the problem solving and decision making approaches are illustrated in Tables 1 through 11 with defining terms and phrases depicted in bold font from participant responses. These brief responses are illustrative of the participants' responses throughout the interviews, providing support for the labels and categories.

For Table 1 and the Ultimate Decision Maker viewpoint, Participant 101 provided the most responses overall to the question regarding an Approach to Decision Making and Problem Solving. Yet, this participant's responses related to personal, individual decision making rather than any assistance in solving problems or discussion of group or collaborative decision making, for example, "A lot of consultation, a lot of consensus building, but ultimately, I'm the guy who has to make the decision." Participant 101 spoke of approaches to decision making more than twice that of the next participant of the randomly selected participants. In fact, compared against all participants within the study, this participant provided the most responses related to decision making, but those responses did not relate to how this senior manager helped employees solve problems. In fact, very few participants could illustrate any approach to identifying problems, and very little discussion occurred with regard to problem identification.

Table 1: Ultimate Decision Maker Viewpoint

Participant Interview Viewpoint vis-à-vis Problem Solving and Decision Making Approaches

\section{Participant Problem and Participant Responses}

Decision Approaches

101 Academic I'm thinking of my characteristics. I'm a person who is impatient with

Group Problem Solv- meetings, group meetings. I'm much more comfortable with small ing/Individual Decision groups: two or three of us talking about this issue that's relevant to

Making us. And then move on to the next one. Consensus. So, I think you would call it consensus building, at least.

With Participants 102 and 118, the Skilled Manager viewpoint, as shown in Table 2, the combined view of individual or group problem solving with individual or group decision making was identified. These approaches were revealed through the participant's emphasis on using the most basic level of decision making, incorporating the primary people, or making decision at the apex of the organization. Similar and succinct examples related to mental models held by the participants were derived from Participant 102 and the use of participative and transparent. Participant 102 provided an example of how cooperation and collaboration were used interchangeably during a discussion of the organization. In this reference, the notions of working together and common goal as well as the implied notion of trust relate to collaboration; however, cooperation comes into the participant's definition of collaboration. 
Table 2: Skilled Manager Viewpoint

Participant Interview Viewpoint vis-à-vis Problem Solving and Decision Making Approaches

\section{Participant Problem and Decision Approaches}

102 Academic

Group Problem Solving/Group Decision Making

118 Non-Profit Service Individual or Group Problem Solving/Individual or Group Decision Making
I think the key word here is participative. I believe in getting people involved. I believe in transparency. I believe in letting people know what they are supposed to do and follow through..

Well, we try to get decisions to the most basic level where the issue lies. So, if it's a decision related to services to a consumer, we try to incorporate the primary people that relate to that consumer in the decision making. If it is an issue that's broader...that perhaps is not consumer oriented but maybe more macro...something that would affect our image or our reputation, those decisions are really made at more of the strategic apex of the organization. So, they would be made by me, our senior program director and/or our board of directors.

Within Table 3 and the Chain of Command viewpoint, Participant 103 provided support and illustrated the interchangeable as well as the combined use of cooperation and collaboration. In addition, this description also included the discussion of a structured and hierarchical environment, which runs counter to collaborative efforts. Several references of time cover extended periods. For instance, Participant 103 states that some assignments "could be a year or it could be a couple of months but not more than a year and one half to two years. You are not 100 percent dedicated to that project. That project is just one of your jobs at the time." From this example, the coordination of additional work efforts occurred not only over short periods but often over extended periods along with multiple, parallel project assignments.

Referencing leadership as a descriptive term, Participant 106 stated that "the art of leadership is getting people to follow the rules. ...And, that is where the leader has the touch, that's the magic." Interestingly, Participant 106 was located in both groups, that is, the military environment was described as both a learning organizational environment as well as a controlling or competitive organizational environment. In terms of learning organization, this participant touted the opportunities the military provided for educational experiences. However, from this participant's viewpoint, the individual needed to take advantage of these opportunities in order to be considered for advancement in this competitive, military environment. Thus, a learning environment and a competitive environment can and do exist. Most discussions by these participants focused on the need for senior managers to balance controls or apply the appropriate controls rather than to maintain or increase controls within their organizations. With all participants' responses, little or no relationships were made between the discussion of controls to problem solving, decision making, and collaboration within the organizations. 
Table 3: Chain of Command Viewpoint

Participant Interview Viewpoint vis-à-vis Problem Solving and Decision Making Approaches

\begin{tabular}{l}
$\begin{array}{c}\text { Participant Problem and } \\
\text { Decision Approaches }\end{array}$ \\
\hline
\end{tabular}

103 Military

Group Problem Solv-

ing/Group Decision Making

106 Military

Individual Problem Solving/Individual Decision

Making
We also have ORM, Operational Risk Management, which can be used for any level of decision. You take a look at the problem and identify the risks and the impact of those risks on the organization. And, you make decisions based on possible impact, whether the value outweighs the risks.

I like to walk the shop because I like to hear and see and understand the fellas, but I will tell you that walking the shop as you heard me say, I'm sensitive to the chain of command when I do that, and that's all about the sense of trust. Trust is very important in our business. So, I trust the leadership, and I trust the guys, and they have to trust me so that when I go out there, I'm not going to compromise that level of trust. If somebody wants to confide in me over some issue, and that's a trustworthiness that I now have.

For the Organizational Change viewpoint, Table 4 illustrates the primary focus of these participants. Participant 104 discusses a problem solving methodology and Participant 114 identifies subject matter experts. At the other end of the spectrum was Participant 111 within the academic category. This participant's discussion covered students and administrators stating "the majority of the policies are governed and disseminated through our course catalogue... so they understand their responsibilities as students and our responsibilities as administrators as a university, providing service to them."

In general while participants' primary attention did not focus on policies, procedures, and rewards for their employees, senior managers were aware of those factors and attempted to maintain a balance within their organization, especially when going through change. Depending on the organization's culture and structure, applicable laws and regulations, and its guiding mission, these senior managers established fully defined or broadly outlined policies and procedures. In addition, these senior managers ensured or supported the proper application of these policies and procedures, depending upon the level of control they felt necessary for accurate decision making.

Table 4: Organizational Change Viewpoint

Participant Interview Viewpoint vis-à-vis Problem Solving and Decision Making Approaches

Participant Problem and

Decision Approaches

104 Business

Group Problem Solving/

Group Decision Making

110 Academic

Individual Problem Solving/

Individual Decision Making

\section{Academic}

Individual Problem Solving/

Individual Decision Making

\section{Participant Responses}

We first start out looking at what's going on in the industry and how we compare to the external environment. ...do a gap analysis to see what the issues are and then we head it off internally to see what our weaknesses are and then what our strengths are.

But, it's not a real strict procedure that we have or very formal, I should say, procedure that we have, but you know, people know my door is open, people have access to me all the time, they can come and say I have concerns.

I would say spanning across the organization, organization-wide, I believe for the most part probably decisions are made from the top down not collaborative or empowering the employee to make the decision. And, also sometimes decisions are made within a silo instead of across the departments. 


\begin{tabular}{ll}
\hline $\begin{array}{c}\text { Participant Problem and } \\
\text { Decision Approaches }\end{array}$ & \multicolumn{1}{c}{ Participant Responses } \\
\hline $\begin{array}{l}\text { 114 Business } \\
\text { Group Problem Solving/ } \\
\text { Group Decision Making }\end{array}$ & $\begin{array}{l}\text { I would say that we solve problems through a team approach. Teams } \\
\text { are assembled with subject matter experts and technically in a team that } \\
\text { would be a multi-disciplinary group of folks. Some of which who would } \\
\text { be subject matter experts that may speak to details that relate to solving } \\
\text { the problem at hand. ... Now, we do problem solving at an individual } \\
\text { level. There are individual contributors, but typically that's not the case. } \\
\text { There are groups of three or four or even more in some cases that it takes } \\
\text { to solve. It depends on the magnitude of the problem as well.... teams } \\
\text { are critical because there's so many components and aspects of an issue } \\
\text { that we have to make sure that all those issues are covered and that we } \\
\text { don't leave out anything or not consider some key component of a prob- } \\
\text { lem in the final analysis. } \\
\text { Yes, the military itself or the Army has what's called the Military Deci- } \\
\text { sion Making Process (MDMP). And, this is primarily associated not } \\
\text { so much with making decisions but it's a planning approach. And, } \\
\text { this is how you would develop a plan like say how would we invade Iraq } \\
\text { or for instance the surge that went by about two years ago. }\end{array}$ \\
115 Military &
\end{tabular}

As depicted in Table 5, the Partnership viewpoint illustrates the use by Participant 105 of decentralized and partnership. These terms reflect this participant's mental model of the organization and the relationship to this participant's decision approach. Some participants were concerned about aspects of their organization's policies, procedures, and rewards; most participants limited that aspect. However, Participant 105 presented the greatest concern for policies, procedures, and rewards primarily due to the laws and government regulations covering the organization. Even though the reference from Participant 105 illustrated the greatest concern for policies and procedures, very little of the participant's dialogue depicted individual rewards other than in terms of the partnership stating that "One of those objectives is certainly turning a profit and sharing that with constituents."

Table 5: Partnership Viewpoint

Participant Interview Viewpoint vis-à-vis Problem Solving and Decision Making Approaches

Participant Problem and
Decision Approaches

105 Business

Individual Problem Solving/

Individual Decision Making
One thing that is critical if you look at our industry...the business we're in is in essence part of the product and or service if you call it that we provide to our clients is really problem solving. So, in many cases, what we do for a living is to help clients either work through challenges or issues. ... But, a lot of the decision making on most of the aspects of what we have to decide is decentralized. It really, the structure of a partnership, is such that each partner is expected to solve problems and or reach decisions on actions going forward.

As seen in Table 6, the Unencumbered Innovation viewpoint of Participant 107 was enhanced by the use of group problem solving and group decision making. This participant incorporated terms such as teams, working together, limited bureaucracy, and reduced friction to solve problems. These terms provided insight into the mental model held by this participant in relation to problem solving and decision making. In addition, Participant 107 provided insights into the relationship between organizational structure and culture with a discussion of the struggle to form a culture and limit structure so that innovation occurs freely and unencumbered. Yet, Participant 
117 from the military category talked directly to personal management styles and strategies rather than any collaborative efforts. In the discussion, this participant spoke of developing relationships and equated managing to the identification of learning experiences for the individuals. The participant felt the learning opportunities and mentorship allowed these individuals to become successful leaders themselves, creating an unencumbered and innovative environment.

Table 6: Unencumbered Innovation Viewpoint

Participant Interview Viewpoint vis-à-vis Problem Solving and Decision Making Approaches

Participant Problem and
Decision Approaches

107 Business

Group Problem Solving/

Group Decision Making

\section{Military}

Individual or Group Problem Solving/Individual or Group Decision Making
And, the company was sort of started on this principle that you can have small teams working together very closely, and if you remove a lot of process and what's loosely termed as bureaucracy from the system, you reduce the amount of friction they have to solving a problem, and you enable them to make a lot of progress very quickly.

The organizational approach to solving problems is more a structured approach. We are pretty much governed by rules and regulations on what we do and what we can and cannot do, depending on what the issue is and where in particular we are working. I have some leverage as far as the things that I can do as long as it's not something that's in law or anything that's needs to be authorized by a higher authority without having their permission to do so. And, depending on how much trust they have in you, you pretty much have a lot of latitude.

With the singular viewpoint of Family Oriented Service, Participant 108 presented the notion of institutionalized decision making. Here problems were solved and decisions were made in order to protect the organization as well as the individuals served. As the organization's top manager, this participant felt it was necessary to make and own the final decisions.

Table 7: Family Oriented Service Viewpoint

Participant Interview Viewpoint vis-à-vis Problem Solving and Decision Making Approaches

Family Oriented Service Viewpoint

\begin{tabular}{ll}
\hline $\begin{array}{c}\text { Participant Problem and } \\
\text { Decision Approaches }\end{array}$ & \multicolumn{1}{c}{ Participant Responses } \\
\hline 108 Non-Profit Service & $\begin{array}{l}\text { I think we are institutionalizing many of our decision making proce- } \\
\text { dures and processes and that means we're deriving policies and pro- } \\
\text { cedures and ways of doing business and make decisions. We also are } \\
\text { trying to retain some of our grass roots feel. }\end{array}$ \\
Individual Problem Solving Decision Making
\end{tabular}

Within Table 8, the viewpoint of the Voice of the Customer is identified. Along with the focus on group problem solving and group decision making, Participant 109 provided insights regarding collaboration and management of organizations. This participant felt that the structure of this organization was a "conscious decision." Looking across other business organizations, Participant 109 felt the structure and design related directly to decision making with regard to its customers. Participant 109 spoke of how technology tools allowed the organization to be effective and efficient, enabling rapid customization of their products and services while maintaining high quality. Those technology tools included email, electronic calendars, office applications, Intranets for knowledge sharing, wikis, blogs, and Internet connections that allowed browsing, searching, and web conferencing as well as video teleconferencing. 
Participant 113 spoke to the dynamics that occur at the headquarters office and the organization's customer focus. This participant felt that without the advantage of co-location, individuals miss the dynamic and lose the informational and social aspects of working together. These discussions of presence and place can be compared to elements of asynchronous (serial) and synchronous (parallel) time. For blended presence to function properly, it is apparent that organizations must support their members through its culture, social networks, and technology tools.

Table 8: Voice of the Customer Viewpoint

Participant Interview Viewpoint vis-à-vis Problem Solving and Decision Making Approaches

Participant Problem and
Decision Approaches

$\begin{array}{ll}\text { 109 Business } & \begin{array}{l}\text { I think it is primarily a root cause analysis focus. So, because of our } \\ \text { particular industry and the criticality of making sure that we have zero } \\ \text { errors because we have a direct impact on people's lives and their health } \\ \text { Group Decision Making } \\ \text { that we work very hard to make sure that we do not replicate an error or }\end{array} \\ \begin{array}{l}\text { a mistake. } \\ \text { I13 Business }\end{array} & \begin{array}{l}\text { It ties into problem solving as well because if we need to make invest- } \\ \text { ments in features and functions, those trade offs will be balanced first. }\end{array} \\ \text { Group Problem Solving/ } & \begin{array}{l}\text { And, then again, those trade offs are typically versus new features and } \\ \text { functions to gain basically or drive market share or get ahead of our } \\ \text { competitors. But what's not pervasive in our culture, that I've seen in } \\ \text { many other companies that we work with, is that we don't save costs at } \\ \text { the expense of all else. Every decision has a value assessment and } \\ \text { those investments are calculated accordingly, and that's pervasive } \\ \text { within the organization. }\end{array}\end{array}$

With the Policy Implementation viewpoint, Participant 112 indicates that problem solving and decision making are not the focal point of this type of senior managers. Rather, as shown in Table 9, the problems to be solved involve carrying out the decisions made by others at even higher levels of the governmental organization. It is not so much an abdication of responsibility, problem solving, and decision making but an acceptance of the level of authority and responsibility.

Table 9: Policy Implementation Viewpoint Participant Interview Viewpoint vis-à-vis Problem Solving and Decision Making Approaches

\section{Participant Problem and Decision Approaches \\ Participant Responses}

112 Government

Decision Implementation
So, problem solving, I think in a public sector entity like mine, is very different than problem solving in the business sector and across other public agencies. I think that each public sector entity has specific things that are part of its goals and objectives. So, in my case, it's policy implementation and so it's not so much problem solving as it is how you implement this policy.

While Participant 116 and Participant 120 hold the World-Class Combatant Power viewpoint, these participants take near opposing positions with regard to problem solving and decision making. With Participant 116, the approach appears to be a combination of group problem solving and then individual or group decision making. This participant's focus is on planning combat missions. The group problem solving or planning process came to the front as well as group decisions during the planning process; however, chain of command took over when making the final decision due to the hierarchical structure of the military and relation to the government. Participant 116 provides insights into the importance of technology tools for the military. According to this participant, the primary use of these technology tools enabled communication and coordina- 
tion. Interestingly, Participant 120 speaks of communication and coordination, yet illustrates individual problem solving and individual decision making. Significant in all references is that no participant described a collaborative, decision making practice within the organization.

Table 10: World-Class Combatant Power Viewpoint

Participant Interview Viewpoint vis-à-vis Problem Solving and Decision Making Approaches

Participant Problem and
Decision Approaches

116 Military
Group Problem Solving/
Individual or Group Deci-
sion Making

I would say that is a process that applies to anticipating major combat operations down to the way in which specific tactics are executed within an operation. So, it's a process of anticipating what issues you are likely to face and trying to lay out a structure by which you're going to attack those issues and be able to modify that plan as required to capture experience to create a more realistic in the future based on experience.

120 Military

I would make sure that the problem they are trying to solve or the Individual Problem Solving/ Individual Decision Making

$$
\begin{aligned}
& \text { opportunity they are attempting to exploit or advance to put it in a } \\
& \text { more positive vane I would just ensure that their efforts are in line } \\
& \text { with overall strategy and goals and objectives in the organization. I } \\
& \text { would ensure that the problem that they are trying to solve or the oppor- } \\
& \text { tunity that they are trying to exploit. It is of sufficient priority according } \\
& \text { to the goals and objectives. I would make sure that their efforts and my } \\
& \text { efforts are in alignment with strategy and that they are not going after } \\
& \text { something that might not need to be addressed or that is so small that } \\
& \text { their efforts are being wasted in that it's not a good use of time. What I } \\
& \text { would do is that I would try to help the individual find the solution to the } \\
& \text { problem or frame their efforts. I would let my direct reports know that } \\
& \text { this person is working on this particular effort, and I will ensure that } \\
& \text { backward resources find money, space, whatever help he needed were } \\
& \text { allocated for this person. I would ensure that the conditions were set for } \\
& \text { this person to give their best effort and try to accomplish what they set } \\
& \text { out to do. }
\end{aligned}
$$

Finally, Table 11 depicts the Multi-Facetted Organization viewpoint with Participant 119. This participant described group problem solving and individual decision making approaches within the interview context. When asked to provide adjectives describing the organization, this participant's comments fell into the areas of collaboration versus cooperation, leadership, and management. Regarding collaboration versus cooperation, Participant 119 felt that collaboration differed from cooperation in that when people collaborate "they come to the table, and they are willing to give up something for the greater good." Most participants used collaboration and cooperation interchangeably and often with the notion of consensus and cooperation in terms of decision making. 
Table 11: Multi-Facetted Organization Viewpoint

Participant Interview Viewpoint vis-à-vis Problem Solving and Decision Making Approaches

Participant Problem and

Participant Responses

Decision Approaches

119 Non-Profit Service

Group Problem Solving/

Individual Decision Making

I'm speaking from the context or the vantage point of a Vice President that's over the fund raising, communications, external relations part of the organization, which gives me a pretty good vantage point because I work across all programmatic areas. So, in terms of the general kind of approach that we take to problem solving, I would say we have a very inclusive process... a process that draws on the expertise of lots of people, and there's a lot of capabilities across this organization among staff. So, I think they are pretty good about getting a lot of different view points and then I don't think people are afraid to make decisions, but I think that people like to make informed decisions with lots of input.

Results Summary. In general, academic participants spoke to their personal decision making abilities, changes to their organization, and management skills. Business participants focused on customer relations, innovation, organizational change, and partnerships. Most military participants focused on either chain of command or combat power capabilities with those Navy participants also speaking to unencumbered innovation. Service organization participants identified and stated family orientations or multi-facetted perspectives due to their multiple missions along with their vital management skills in leading non-profit service organizations. The government participant assumed the interview viewpoints of policy implementation, that is, the participant's role in carrying out defined policy rather than identifying and solving specific problems or imposing solutions.

The analyzed transcripts, the identified viewpoints, and the example references further illustrate the perspectives of senior managers regarding their lack of understanding and interchangeable usage of collaboration and cooperation. In addition, when relating collaboration to problem solving and decision making, only 10 out of the 20 participants provided comments connecting collaboration to these areas. The lack of discussion linking collaboration and decision making illustrates the perception of these senior managers with regard to how decisions are made within their organizations. This research result identifies an individual approach compared to any collaborative efforts for the senior managers of the organizations within this study.

Much of their notions regarding leadership and management are just as individualized and personalized as the participants' positions and limited notion of collaboration. As illustrative of the 20 participants of the study, these participant references provide insights into the perceptions of each senior manager. As depicted by their interview viewpoints and their responses to these probing questions, the participants' responses illustrate the measure of how senior managers helped or did not help employees solve problems and make decisions.

Participants indicated that management was responsible for the culture and structure within an organization and that trust was an important component for success. Participants also provided insights into the relationship between organizational structure and culture. Most participants indicated their concern with balancing structure and hierarchy to maintain the desired culture whether academic, business, military, and service or government. Organization culture, structure, and model are intrinsically tied together for the majority of the participants.

When discussing technology tools, the notion of the organization's working environment arose. While these notions covered the gamut of technology tools, none of the senior managers could indicate how these tools helped employees collaborate or solve problems. Participant 116 from 
the military category provided the most insights compared to Participant 107 from the business category or Participant 118 from the non-profit service category with the least discussion coming from the participants within the academic category. While minimal differences were expected in the discussions between the military and business categories, the difference between the military and academic categories was not expected. In fact, there were dramatic differences among these participants when discussing technology tools either used or being considered for use within their organizations.

Most participants spoke of their organization in terms of a blended (co-located and virtual) work presence for their employees rather than completely co-located or completely virtual. A colocated presence meant that employees conducted their work at the organization's building or buildings. Employees have a physical presence. A virtual presence meant that employees work remotely, possibly from their home. A blended presence meant that employees work co-located as well as work virtual from their home or from another office location across the country or around the globe. Work functions can be serial or asynchronous and follow other functions. Work functions can be parallel or synchronous and occur along side other functions, for example, project tasks that are sequential or meetings held in parallel. These work functions whether serial or parallel must be completed at a specified time. In addition to the notion of presence, all participants spoke of time in some manner. Whether framed in years, months, days, or minutes, these senior managers mentioned timeframes that related to the operation of their organizations and members. From this study, it became apparent that the managers' sense of time was asynchronous, that is, serial. But the organization environments were most often co-located and virtual, that is, blended presence, requiring coordination of serial and parallel work functions. Due to the blended presence, employees and members may work in different time zones, varying by many hours.

The results of this study illustrated senior managers' difficulties in balancing elements of their organizations in order to achieve desired outcomes. That said those same managers demonstrated a lack of awareness or an inability to help employees solve problems. This inability was illustrated in their difficulty to answer the primary question directly with specific responses and examples. Senior managers' lack of understanding affected their own approach to problem solving and decision making with regard to their organizations. In addition, most senior managers had difficulty differentiating between collaborative and cooperative activities. During the interviews, each senior manager assumed an organizational viewpoint or focus, that is, a singular perspective that framed the responses. This participant interview viewpoint became the primary component to further analyze senior managers' responses from the questions covering problem solving, problem identification, decision making, collaboration and cooperation, organizational cultures and structures, and technology tools as well as ways of working: guiding principles; policies, procedures, and rewards; environment, presence, and time.

\section{Discussion}

Historically, research on problem solving, decision making, and collaboration examined the individuals involved, the situation, the methods used, and the results obtained during the process. This study moved to a meta-level of research and analysis regarding problem solving, decision making, and collaboration. This research effort investigated how senior managers perceived their actions to enable employees or organization members solve problems and make decisions, especially wicked problems with no single, right solution or absolute, appropriate response. In addition, this study examined senior managers' understanding of collaboration and collaborative activities vis-à-vis cooperation. Thus, the focus for this study was on those who were in a position to enable or hinder problem solving, decision making, and collaboration within their organizations. Senior managers establish or contribute directly to the organization's vision, mission, and 
goals. Those senior managers define the organization's culture, structure, and major operations. And, those managers approve or reject funding for technology tools meant to facilitate collaboration and decision making, that is, the work of individuals within their organization and their relationships to the organization's external environment. These elements identified during this study illustrate a specific viewpoint of senior managers' perceptions and their relationships to the decisions made.

Employee Decision Making. Employees or organization members strive to make appropriate decisions. Their decisions may affect their team, functional area, cut across their organization, extend to external stakeholders, present life and death situations, or have global consequences. In these various situations, individuals may face simple, complex, or wicked problems. These wicked problems require dynamic, synergistic responses from the individuals involved. The responses require identification and communication of information as well as coordination of efforts. Individuals must work together in a dynamic and synergistic environment. Collaboration comes to the forefront when solving wicked problems. However, the responses of senior managers indicated their limited involvement in helping employees or organization members solve wicked problems. This limited involvement was revealed during the interviews more often by what was not said rather than what was said (Argyris \& Schön, 1996). When asked how they helped employees solve problems, senior managers were unable to cite specific instances or methods used other than describing the meetings they held, speaking of their personal decision making strategies, or listing their management skills. Their lack of specific responses and examples to the direct question indicated that this notion was foreign to these senior managers. While it is generally understood senior managers focus on the strategic initiatives and planning of their organizations (Mintzberg, 1994; Shapira, 2002), the value of that focus becomes questionable due to the managers' lack of awareness of how those strategic decisions and plans might be applied to identifying and solving middle and lower level problems, especially wicked problems, and facilitating decision making.

Senior Manager Decision Making. Most senior managers can speak to their organization's mission, vision, and goals to varying degrees and discuss their planning process. Yet, instantiation, communication, and execution of those organizational elements often fall short of the expected results. The ability to diagnose failing strategies and plans and then adjust directions quickly to dynamic situations requires senior managers to be sensitive to the prevailing internal and external environments. While the advice of external consultants, status of direct reports, and monthly dashboards of primary projects may provide guidance, this information is based on limited perspectives, numerical values, and abbreviated summaries. The brevity, selectivity, and possible bias of these data points often do not present a full depiction of the situation to enable adequate decision making on the part of these senior managers. In turn, this situation may negatively affect any methods that might be used by those managers to help employees or members solve problems.

Organizational Policies and Procedures. When it comes to organization culture and structure (Hofstede \& Hofstede, 2005; Schein, 1992), senior managers state they are responsible for the culture and structure of their organizations, and those managers describe their struggle to create a structure that supports the culture. In most instances, culture is described on a continuum by these senior managers. This continuum describes degrees of control from relatively strict to relatively free for employees or organization members to act and make decisions. Yet, the structure is most often described as hierarchical, even by those senior managers who strive to provide an atmosphere for independent action. Only in discussions of partnerships or highly entrepreneurial groups are relatively flat structures presented or, rather, relatively less hierarchical structures presented. This situation presents a paradoxical situation. If senior managers expect employees or organization members to act and make decisions, the hierarchical structure requires decision making to 
filter up, which requires cooperation and limits collaboration and decision making at lower levels. In addition, senior managers are unaware of methods to enable employees or organization members to solve problems. Senior managers are not facilitators; these managers are receptors of facilitated action. Perhaps, this lack of awareness is due to the paradoxical situation created by a structure that does not support the desired culture, preventing dynamic action, that is, collaboration and stifling decision making.

Technology. Addressing the policies, procedures, and rewards, senior managers again expressed their struggle to balance these elements with the desire to reduce or eliminate unnecessary paperwork and reporting practices. Most often policies and procedures were discussed in terms of accounting, legal, and regulatory requirements, but these elements were also discussed in terms of flexibility for personal issues related to employees or organization members. Generally, it was the type of organization rather than its structure which governed this area. Most senior managers were certain the policies and procedures existed where necessary; however, they could not state how often these elements were updated, the process, or the specific delivery system. The lack of discussion regarding rewards is telling. If the reward system is not structured to incent individuals towards collaboration, the organization culture and structure does not provide the supporting architecture, and the senior managers do not enable or facilitate problem solving and decision making, the inability for employees or members to collaborate and make decisions becomes obvious. This situation may not result in organization failure, but the situation may result in inefficiencies and negatively affect achieving overall goals.

Technology Tools. In terms of technology tools, most senior managers could name the typical office products, for example, word processing and analytical software, email, electronic calendars, database applications, and instant messaging. These managers also stated the importance of the Internet for information and external communication, including web presentations. Intranets, wikis, and blogs were identified as knowledge bases for their organizations. Teleconferencing and video teleconferencing were also mentioned as vital sources of communication among employees or organization members; however, the often poor quality and high cost of video teleconferencing (VTC) were cited continually as prohibitive factors in the frequent and general usage of this technology tool. Those in the military did express the need to use VTC when making combat plans and decisions so that the body language of those individuals involved could be taken into account as senior managers made their decisions. No specific technology tool was mentioned or described as collaborative software other than Microsoft's Sharepoint, which is, in fact an Intranet application that can be extended to Extranet capabilities to allow for information storage and knowledge sharing outside the specific organization. In addition, no specific technology tool was mentioned or described as problem solving or decision making software. Most senior managers could not describe features or list requirements for technology tools that would enable their organizations' members to solve problems, make decisions, and collaborate effectively.

Senior Manager Role. Senior managers emphasize their role in determining their organization's culture and structure and in defining its mission, vision, and strategic direction. Yet to varying degrees, senior managers provide little support for enabling problem solving and decision making at lower levels. And to varying degrees, senior managers fail to differentiate between collaborative and cooperative activities within their organizations. If senior managers cannot take these aspects into account in fulfilling their roles, it is doubtful these managers can effectively manage the structure and strategic direction of their organizations and, in turn, define and approve technology tools to support collaboration and decision making.

Organizational Theory and Decision Making. Organization theories and decision analysis furnish insightful and related viewpoints of how those within organizations perceive their problem solving and decision making situations. Researchers incorporate that information into models to illustrate the factors that affect the components making up the environment in which the decisions 
take place. Organization models and decision making theories are used extensively and have become prescriptive in terms of economic evaluation, risk mitigation, strategic and tactical, procedural, and overall situation analyses. This study has culminated in the ability to illustrate these factors in a coherent fashion through an organization model. The model describes not only the problem solving and decision making situations but also depicts those situations that better support collaborative problem solving and decision making in organizations.

\section{Organization Model}

Other researchers have modeled organizations in various ways, depending upon their research focus. For example, Mintzberg (1980) illustrated the structure of an organization in terms of five basic parts consisting of an operating core, middle managers, apex, technology, and support staff. His model illustrated elements of the organization that could be permutated to change the overall design of the organization. The model provided an internal perspective and limited components.

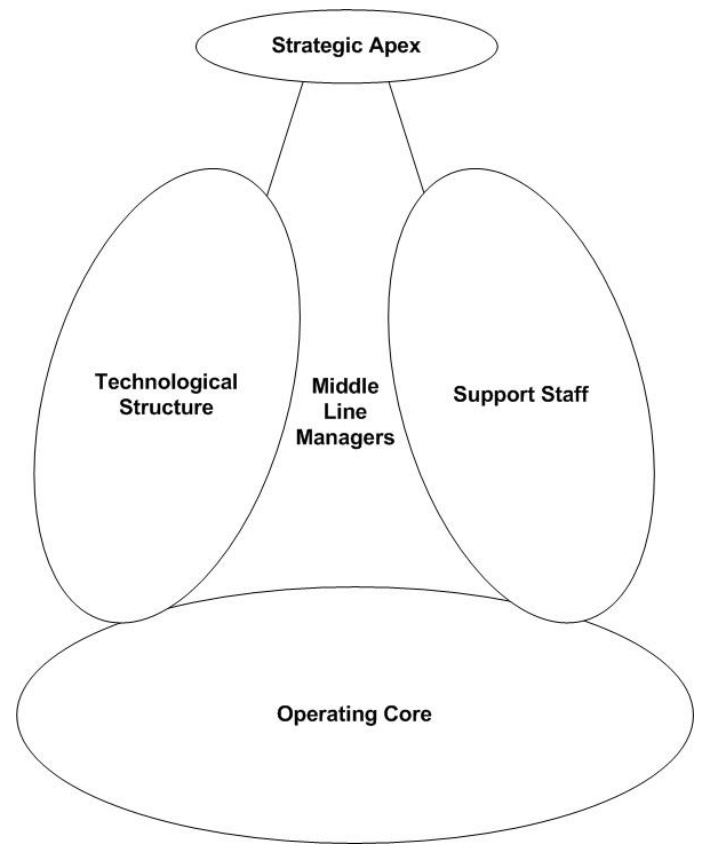

Figure 1: Five Basic Parts of an Organization

Rugman and D'Cruz (2000) modeled the structure of a flagship multinational organization. In comparison with the Mintzberg model, the Rugman and D'Cruz model identified external relationships, including partners, competitors, and government influences. This model provided additional perspectives but did not illustrate the internal workings of the organization, that is, the components or functions identified as strategy, management, and operational. 


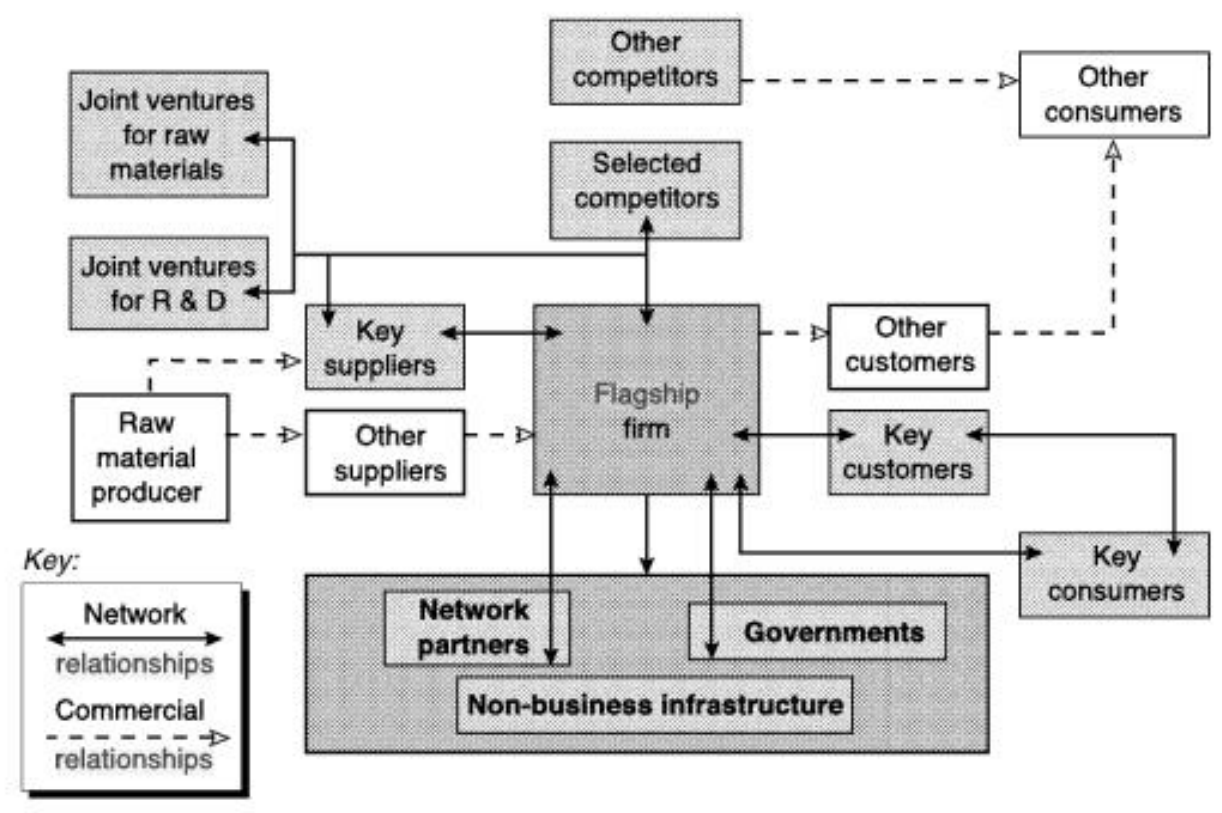

Figure 2: Structure of a Flagship Organization

The organization model developed from this study illustrates the connections between an organization's external environment and its internal environment as applied to the decision making abilities of those within or related to the organization. The model depicts a continuum from a controlling to a collaborating organization as well as the primary components of the organization with regard to problem solving and decision making. The terminology derived from the research literature and compared with the managers' responses and organizational idioms provided the additional components of the organization model.

Whether in academic, business, military, non-profit service or government organization, the manner in which senior managers described how they enabled or did not enable employees solve problems often came in terms of mission and vision, strategic goals and tactical objectives, costs, risk mitigation, established procedures, and relationships. Thus, the principles, practices, and processes also range from controlling where managers command the activities and tasks of the workers, the practices are restrictive inflexible, and allow no deviation or creativity on the part of the workers. The processes are serialized and do not facilitate group, team, or any collective activities.

In a controlling organization, the technology and information are also restricted without reason or cause. And, physical presence of the workers is required. Whereas, a collaborative organization is flexible and builds on relationships and trust by encouraging the practice of self-reliance, instituting concurrent processes, promoting the acceptance of virtual presence and communities through free use of supporting technologies and information sharing. Physical and virtual presence is indicated by the internal circles and the color gradations created. Deeper gradation indicates a more physical presence and shallow gradation indicates a more virtual presence.

With the outer-most circle, the model illustrates that organizations function within an external environment. This external environment establishes cultural, governmental, and legal restrictions upon the organization. Senior managers and organization members must take this external environment into account when solving problems and making decisions. Along with the notion of presence, the model also introduces the element of time. All organizations work within some element of time in the delivery of products and services. However, with global operations, or- 
ganizations must come to realize the influence time has on work, solving problems, making decisions, and collaborating. The white and slight depiction of time indicates the limited emphasis placed upon considerations of time by some senior managers as an ongoing element of decision making, collaboration, coordination, and communication. The model presents implications for collaboration, problem solving, decision making, and organization research, especially in the area of technology tools that are needed to support the dynamics of collaboration for groups that reside internal and external to organizations and across time zones. The depiction of technology tools indicates the slightly greater emphasis placed upon those tools in comparison with time, problem solving and decision making methods, and business model or organization focus considered.

Figure 3 depicts the organization environmental conditions from most controlling at its center to most collaborative at its outer edges. Principles, practices, and processes range from controlled actions at the point to independent actions at the broad end. Physical and virtual presence is indicated by the internal circles and the color gradations created. For the inner circles, a deeper color gradation indicates a more physical presence and a shallower gradation indicates a more virtual presence. The influences of problem solving and decision making methods, time considerations and restrictions, business model or organization focus, and overall mission are depicted. The importance of these elements is indicated by the size of their triangle. With the outer-most circle, the model illustrates that organizations function within an external environment. This external environment establishes cultural, governmental, and legal restrictions upon the organization.

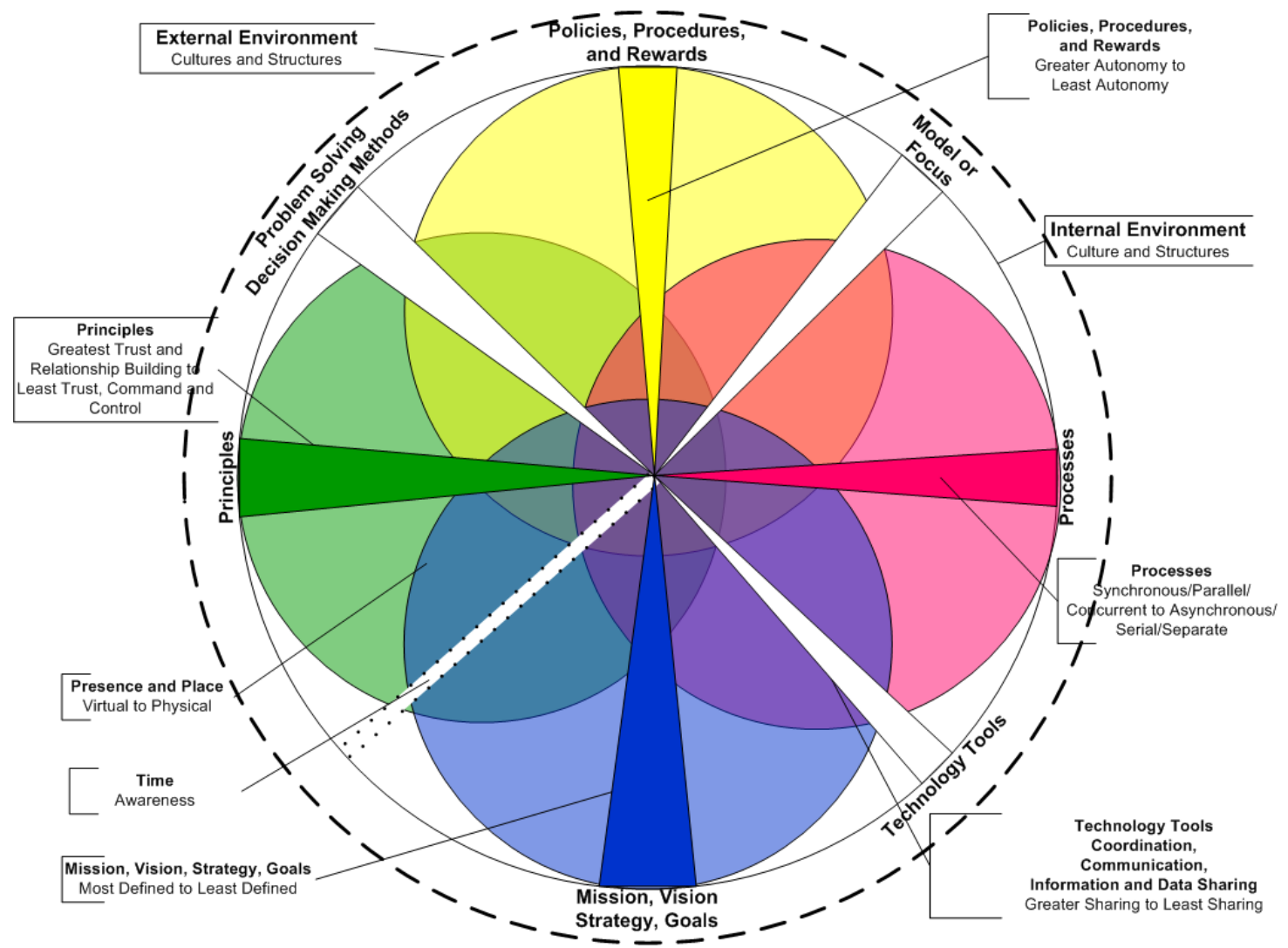

Figure 3: Organization Model

With regard to technology tools, a recent Gartner study predicts the development of a new method of decision support systems - collaborative decision making applications (Schlegel, Sallam, Austin, \& Rozwell, 2009). According to Schlegel, these applications will combine social software with business intelligence systems. The combination will provide decision makers with the ability "to brainstorm options, evaluate their pros and cons, and agree on a course of action" 
(p. 1). The study indicates that combining social software with business intelligence systems will facilitate collaboration and enable informed decisions. However, as this study indicates collaboration and decision making require more than just the ability to brainstorm ideas, tag text, and change workflow, or display key performance indicators, financial information, and project dashboards. A true collaborative decision making application or system must enable problem identification as well as analysis, negotiation, and decision making. These features are especially important when identifying and solving ill-defined, wicked problems.

\section{Conclusion}

This study examined responses of senior managers who were drawn from academic, business, military, and non-profit or government organizations. The interview questions covered decision making, organization structure, collaboration, technology tools, and how senior managers helped their employees or organization members solve problems. Their individual responses were compared to terminology from current research literature. Decision making styles were identified and categorized. All senior managers presented a viewpoint that governed their responses to the interview questions during the interview. These viewpoints melded into 11 categories. In terms of technology tools, these senior managers most often identified databases, calendar and email systems, and video teleconferencing as tools that supported decision making and collaboration. The study showed that a better understanding by senior managers of decision making methods and collaboration may provide improved decisions and generate the impetus for developing and incorporating true collaborative technology tools.

Within all organizations, senior managers are extremely busy individuals. Therefore, the time these managers have to devote to a personal interview is limited. During the interviews, senior managers continued to be aware of other pressing issues. Therefore, full participation was often difficult. This study was also limited in that senior managers do not respond well to a broad question that could open the door for unwarranted statements or information. These managers requested background details, the impetus for the study, and how the information was going to be used. Once the primary question was asked and senior managers had difficulty providing responses, it proved that follow-up probe questions were necessary to drive the discussions. How senior managers helped employees solve problems was derived from inferences from responses to the follow-up probe questions. When calling up senior level managers to participate in interviewbased research, these factors must be taken into account when designing and setting up the research tool. In terms of future research, studies could examine how and why senior managers make decisions as well as how senior managers facilitate decision making when working with their peers both internal and external to their organizations. Future research could also examine the perceptions of employees and members as to how their senior managers help them solve problems, make decision, and collaborate.

The results of this exploratory study could contribute to the existing literature on problem solving, decision making, and organizational design. The study may present a sufficient foundation for further investigation into collaborative decision making in organizations as well as the design and development of appropriate supporting technology tools. In addition, this study may result in an improved organization model for structuring information that could be used by professionals and allow those professionals to call upon this collaborative framework when consulting with senior managers and enable those managers to modify or restructure their organizations in order to better support collaborative decision making activities, including the ability to differentiate among simple, complex, and wicked problems. Professionals may use the model created by this study and test the model further to understand how senior managers and those within their organizations perceive their collaborative problem solving and decision making situations at all lev- 
els and directions. Or, the model may enable new ways of transforming and restructuring organizations in the support of a collaborative environment.

Additional, expanded interview instruments or survey methods, protocol analysis, cognitive task analysis, or ethnographic studies based on the model could be developed for the specific purpose of identifying changes or variations in collaboration activities and the influence those modifications have on decisions according to staged or long-term results. This expansion would be particularly valuable when investigating how solutions to wicked problems are identified, selected, and implemented, providing additional insights into the organization structure, decision making at all levels, and usage of supporting technology tools.

\section{References}

Argyris, C., \& Schön, D. A. (1996). Organizational learning II: Theory, method, and practice. Reading, MA: Addison-Wesley.

Axelrod, R. M. (1984). The evolution of cooperation. New York, NY: Basic Books.

Beers, P. J., Boshuizen, H. P. A., Kirschner, P. A., \& Gijselarers, W. H. (2006). Common ground, complex problems and decision making. Group Decision and Negotiation, 15, 529-556.

Bell, C. (2005). Wise organizations. In J. Courtney, J. Haynes \& D. Paradice (Eds.), Inquiring organizations (pp. 229-271). Hershey, PA: Idea Group Publishing.

Beyerlein, M. M., \& Johnson, D. A. (Eds.). (1994). Theories of self-managing work teams (Vol. 1). Greenwich, CT: JAI Press, Inc.

Boven, L. V., \& Thompson, L. (2003). A look into the mind of the negotiator: Mental models in negotiation. Group Processes and Interpersonal Relations, 6, 387-404.

Brown, J. S., \& Duguid, P. (1991). Organizational learning and communities-of-practice: Toward a unified view of working, learning, and innovation. Organization Science, 2, 40-57.

Cannon-Bowers, J. A., Solas, E., \& Converse, S. (1993). Shared mental models in expert team decision making. In J. N. John Castellan (Ed.), Individual and group decision making (pp. 221-246). Hillsdale, NJ: Lawrence Erlbaum Associates.

Chituc, C.-M., Azevedo, A., \& Toscano, C. (2009). A framework proposal for seamless interoperability in a collaborative networked environment. Computers in Industry, 60(5), 317.

Christensen, C. H. (2000). The innovator's dilemma: When new technologies cause great firms to fail (1st ed.). New York, NY: Harper Business.

Churchman, C. W. (1967). Wicked problems. Management Science, 14(4), 141-142.

Conklin, J. (2006). Dialogue mapping: Building shared understanding of wicked problems. Hoboken, NJ: John Wiley \& Sons.

Connolly, T., \& Koput, K. (Eds.). (1997). Naturalistic decision making and the new organizational context. New York, NY: Oxford University Press.

Corbin, J., \& Strauss, A. (2008). Basis of qualitative research (3rd ed.). Thousand Oaks, CA: Sage Publications.

Cottone, P., Pieti, L., Schiavinato, V., Soru, D., Martinelli, M., Varotto, D., \& Mantovani, G. (2009). "Solving" ambiguity in the virtual space: Communication strategies in a collaborative virtual environment. Cognition, Technology \& Work, 11(2), 151-163.

D'Angelo, F. J. (1975). A conceptual theory of rhetoric. Cambridge, MA: Winthrop Publishers.

DeLuca, D., \& Valacich, J. S. (2006). Virtual teams in and out of synchronicity. Information Technology and People, 19(4), 323-344. 
Denning, P. J. (2009). Resolving wicked problems through collaboration. In B. Whitworth \& A. deMoor (Eds.), Handbook of research on socio-technical design and social networking systems (Vol. 2, pp. 1056). Hershey, PA: Information Science Reference.

Dillenbourg, P. (1999). What do you mean by "collaborative learning"? In P. Dillenbourg (Ed.), Collaborative-learning: Cognitive and computational approaches (pp. 1-19). Oxford, GB: Elsevier.

Dutton, J. E. (2002). Strategic agenda building in organizations. In Z. Shapira (Ed.), Organizational decision making: Cambridge series on judgment and decision making (pp. 81-101). Cambridge, UK: Cambridge University Press.

Einhorn, H. J., \& Hogarth, R. M. (1981). Behavioral decision theory: Processes of illusion of validity. Psychological Review, 85, 395-416.

Ernst, J. (2009). Collaborative decision making and personal knowledge management with R-Objects Pepper. Retrieved October 10, 2009 from http://citeseerx.ist.psu.edu/viewdoc/download?doi=10.1.1.131.4767\&rep=rep1\&type=pdf

Espinosa, A., \& Harnden, R. (2007). Team syntegrity and democratic group decision making: Theory and practice. Journal of Operational Research Society, 58, 1056-1064.

Ferguson, G., \& Allen, J. (2007). Mixed-initiative dialogue systems for collaborative problem-solving. Association for the Advancement of Artificial Intelligence, 28, 23-33.

Fischhoff, B., \& Johnson, S. (2002). The possibility of distributed decision making. In Z. Shapira (Ed.), Organizational decision making (pp. 216-237). Cambridge, UK: Cambridge University Press.

Fischhoff, B., Lichtenstein, S., Slovic, P., Derby, S. L., \& Keeney, R. L. (1993). Acceptable risk. New York, NY: Cambridge University Press.

Fleet, D. D. V., \& Griffin, R. W. (2006). Dysfunctional organization culture: The role of leadership in motivating dysfunctional work behaviors. Journal of Managerial Psychology, 21(8), 698-708.

Franco, L. A., \& Meadows, M. (2007). Exploring new directions for research in problem structuring methods: On the role of cognitive style. Journal of the Operational Research Society, 58, 1621-1629.

Gibbs, G. (2007). Analyzing qualitative data. Thousand Oaks, CA: Sage Publications.

Gordon, T. F., \& Karacapilidis, N. (1997). The Zeno Argumentation Framework. Paper presented at the ICAIL-97, Melbourne, Australia.

Gray, B. (2000). Assessing inter-organizational collaboration: Multiple conceptions and multiple methods. In D. Faulkner \& M. d. Rond (Eds.), Cooperative strategy: Economic, business, and organizational issues (pp. 243-260). New York, NY: Oxford University Press.

Gray, B., \& Wood, D. J. (1991). Collaborative alliances: Moving from practice to theory. The Journal of Applied Behavioral Science, 27(3), 3-22.

Halbesleben, J. R. B., Wheeler, A. R., \& Buckley, M. R. (2006). Understanding pluralistic ignorance in organizations: Application and theory. Journal of Managerial Psychology, 22(1), 65-83.

Hayes, J. R. (1981). The complete problem solver. Philadelphia, PA: The Franklin Institute Press.

Hofstede, G., \& Hofstede, G. J. (2005). Cultures and organizations: Software of the mind. New York, New York: McGraw-Hill.

Jackson, P., Gharavi, H., \& Klobas, J. (2006). Technologies of the self: Virtual work and the inner panopticon. Information Technology and People, 19(3), 219-243.

Jones, P. E., \& Roelofsma, P. H. M. P. (2000). The potential for social contextual and group biases in team decision-making: Biases, conditions and psychological mechanisms. Ergonomics, 43(8), 1129-1152.

Karacapilidis, N., Loukis, E., \& Dimopoulos, S. (2004). A web-based system for supporting structured collaboration in the public sector. Paper presented at the Third International Conference EGOV04, Zaragoza, Spain. 
Karacapilidis, N., \& Papadias, D. (2001). Computer supported argumentation and collaborative decision making: The HERMES system. Information Systems, 26(4), 259-277.

Karsten, H. (1999a). Collaboration and collaborative information technologies: A review of the evidence. The DATA BASE for Advances in Information Systems, 30(2), 44-65.

Karsten, H. (1999b). Collaboration and collaborative information technology: What is the nature of their relationship? Paper presented at the Information Systems: Current Issues and Future Changes. Proceedings of the IFIP WG8.2/8.6 Joint Working Conference, Helsinki, Finland.

Klein, G., \& Hoffman, R. R. (2008). Macrocognition, metal models, and cognitive task. In J. M. Schraagen, L. G. Militello, T. Ormerod, \& R. Lipshitz (Eds.), Naturalistic decision making and macrocognition (pp. 57-80). Burlington, VT: Ashgate Publishing Company.

Lee, J. (1990). SIBYL: A tool for managing group decision rationale. Paper presented at the CSCW.

Lin, Y., \& Beyerlein, M. M. (2006). Communities of practice: A critical perspective on collaboration. In M. M. Beyerlein, S. T. Beyerlein \& F. A. Kennedy (Eds.), Innovation through collaboration (Vol. 12, pp. 53-79). Stamford, CT: JAI Press.

London, S. (1995). Collaboration and community. Washington, DC: Pew Partnership for Civic Change.

March, J. G. (2002). Understanding how decisions happen in organizations. In Z. Shapira (Ed.), Organizational decision making: Cambridge Series on judgment and decision making (pp. 10-30). Cambridge, UK: Cambridge University Press.

Mattessich, P. (2003). Can this collaboration be saved? Twenty factors that can make or break any group effort. Retrieved December 11, 2009 from http://www.nhi.org/online/issues/129/savecollab.html

McHugh, A. P., Smith, J. L., \& Sieck, W. R. (2008). Cultural variations in mental models of collaborative decision making. In J. M. Schraagen, L. G. Militello, T. Ormerod \& R. Lipshitz (Eds.), Naturalistic decision making and macrocognition (pp. 141-158). Burlington, VT: Ashgate Publishing.

Michie, S. G., Dooley, R. S., \& Fryxell, G. E. (2007). Unified collaboration and quality in strategic decision-making. International Journal of Organizational Analysis, 14(2), 130-149.

Mintzberg, H. (1980). Structure in 5's: A synthesis of the research on organization design. Management Science, 26(3), 322-341.

Mintzberg, H. (1994). The rise and fall of strategic planning. New York, NY: Free Press.

Miyake, N. (1986). Constructive interaction and the iterative process of understanding. Cognitive Science, 10(2), 151-177.

Morton, A., Ackermann, F., \& Belton, V. (2007). Problem structuring without workshops? Experiences with distributed interaction within a PSM process. Journal of the Operational Research Society, 58, 547-556.

Mueller, G. C., Mone, M. A., \& Barker, V. L. (2007). Formal strategic analyses and organizational performance: Decomposing the rational model. Organization Studies, 28(6), 853-883.

Newell, A., \& Simon, H. A. (1981). Computer science as empirical inquiry: Symbols and search. In J. Haugeland (Ed.), Mind design. Cambridge, MA: MIT Press.

Nutt, P. C. (2002). Why decisions fail: Avoiding the blunders and traps that lead to debacles. San Francisco, CA: Berrett-Koehler Publishers.

Olson, R., \& Rejeski D. (Ed.). (2005). Environmentalism \& the technologies of tomorrow. Washington, D.C.: Island Press.

Panzarasa, P., Jennings, N. R., \& Norman, T. J. (2002). Formalizing collaborative decision-making and practical reasoning in multi-agent systems. Journal of Logic and Computation, 12(1), 55-117.

Parker, A. M., \& Fischhoff, B. (2005). Decision-making competence: External validation through individual-differences approach. Journal of Behavioral Decision Making, 18, 1-27. 
Payne, J. W. (2002). The scarecrow's search: A cognitive psychologist's perspective on organizational decision making. In Z. Shapira (Ed.), Organizational decision making (pp. 353-374). New York, NY: Cambridge University Press.

Perelman, C., \& Olbrechts-Tyteca, L. (1971). The new rhetoric: A treatise on argumentation. Notre Dame, IN: University of Notre Dame Press.

Radner, R. (1992). Hierarchy: The economics of managing. Journal of Economic Behavior and Organization, 16, 217-260.

Radner, R. (2002). Bounded rationality, indeterminancy, and the managerial theory of the firm. In Z. Shapira (Ed.), Organizational decision making (pp. 324-325). New York, NY: Oxford University Press.

Radner, R., \& Zandt, T. V. (1992). Information processing in firms and returns to scale. Annales d'Economie et de Statitique, 25-26, 265-298.

Rahwan, I., Zablith, F., \& Reed, C. (2007). Laying the foundations for a world wide argument web. Artificial Intelligence, 171(10-15), 897-921.

Rappoport, A., \& Wallsten, T. S. (1972). Individual decision behavior. Annual Review of Psychology, 23, 131-175.

Rittel, H. W. J., \& Webber, M. M. (1973). Dilemmas in a general theory of planning. Policy Sciences, 4, 155-169.

Roberts, N. C. (2000). Wicked problems and network approaches to resolution. The International Public and Management Review, 1(1).

Roberts, N. C. (2001). Coping with wicked problems. In L. Jones, J. Guthrie \& P. Steane (Eds.), International public management reform: Lessons from experience. London: Elsevier.

Rugman, A. M., \& D'Cruz, J. R. (2000). Multinationals as flagship firms: Regional business networks. New York, NY: Oxford University Press.

Saaty, T. L. (2008). Decision making with the analytic hierarchy process. International Journal of Services Sciences, 1(2), 83-98.

Schein, E. H. (1992). Organizational culture and leadership (2nd Ed.). San Francisco, CA: Josey-Bass.

Schlegel, K., Sallam, R. L., Austin, T., \& Rozwell, C. (2009). The rise of collaborative decision making. MediaProducts, 6(8), 1-5.

Schraagen, J. M., Klein, G., \& Hoffman, R. R. (2008). Macrocognition framework of naturalistic decision making. In J. M. Schraagen, L. G. Militello, T. Ormerod \& R. Lipshitz (Eds.), Naturalistic decision making and macrocognition (pp. 1-25). Burlington, VT: Ashgate Publishing.

Schraagen, J. M., Militello, L. G., Ormerod, T., \& Lipshitz, R. (Eds.). (2008). Naturalistic decision making and macrocognition. Burlington, VT: Ashgate Publishing.

Schrage, M. (1989). No more teams. New York, NY: Currency Doubleday.

Shapira, Z. (Ed.). (2002). Organizational decision making. Cambridge, UK: Cambridge University Press.

Simon, H. A. (1959). Theories of decision-making in economics and behavioral science. The American Economic Review, XLIX(June), 253-283.

Simon, H. A. (1997). Models of bounded rationality: Empirically grounded economic reason (Vol. 3). Cambridge, MA: The MIT Press.

Sterman, J. D., \& Sweeney, L. B. (2005). Managing complex dynamic systems: Challenge and opportunity for naturalistic decision-making theory. In H. Montgomery, R. Lipshitz \& B. Brehmer (Eds.), How professionals make decisions (pp. 57-90). Mahwah, NJ: Lawrence Erlbaum.

Straus, D. (1993). Facilitated collaborative problem solving and process management. In L. Hall (Ed.), Negotiation: strategies for mutual gain (pp. 28-40). Thousand Oaks, CA: Sage Publications. 
Straus, D. (2002). How to make collaboration work: Powerful ways to build consensus, solve problems, and make decisions. San Francisco, CA: Berrett-Koehler Publishers.

Toulmin, S. E. (1980). The uses of argument. London, GB: Cambridge University Press.

Weill, P., \& Aral, S. (2006). Generating premium returns on your IT investments. MIT Sloan Management Review, 47(2), 38-49.

Witteloostuijn, A. V. (1997). Internal contexts and external environments. In A. Sorge \& M. Warner (Eds.), Handbook of organizational behavior (1 ed., pp. 163-172). Boston, MA: International Thomson Business Press.

Yates, J. F. (1989). Judgment and decision making. Chichester, England: Wiley.

Zsambok, C. E., \& Klein, G. E. (Eds.). (1997). Naturalistic decision making. Mahwah, NJ: Lawrence Erlbaum Associates.

\section{Biographies}

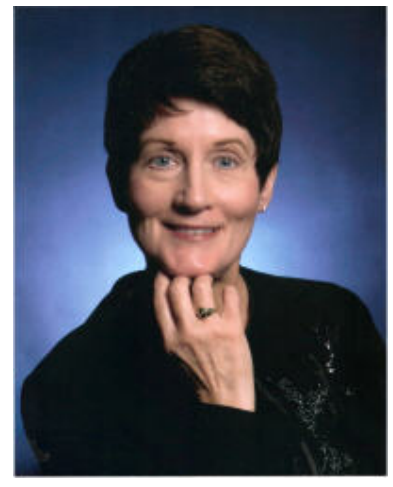

Honora M. Rockar, D.Sc., Senior IT Project Manager at Coventry Health Care has over 30 years of project management in communication networking protocols, remote access servers, financial transaction servers, and web servers as well as end-user software development and documentation. She is certified by the Project Management Institute. She holds a bachelor degree from the University of Pittsburgh, a graduate degree from Carnegie Mellon University, and a Doctor of Science in Information Systems and Communications from Robert Morris University. Her research interests are decision making and problem-solving, organizational design, collaboration, and supporting technology tools.

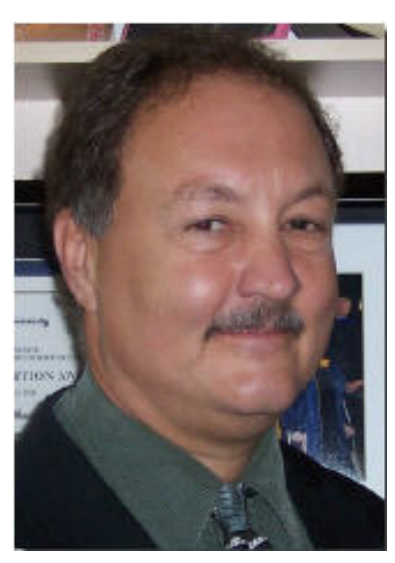

Frederick G. Kohun, Ph.D., Associate Provost and University Professor at Robert Morris University in Pittsburgh, Pennsylvania has more than 35 years experience as a professor, department head, and academic administrator in the economics, policy and information systems fields. He holds a bachelor degree in economics from Georgetown University, graduate degrees in economics and information science, from the University of Pittsburgh, and a Ph.D. in applied history in technology from Carnegie Mellon University. At Robert Morris University he led the design and implementation of eight technology based academic programs at the undergraduate and graduate level (including a doctoral program) as well as the attainment of ABET-CAC accreditation $\mathrm{He}$ is known both nationally and internationally from his numerous publications and presentations in health informatics, decision support, technological impact, and culture as well as his active involvement as an accreditation evaluator and team leader. In 2007, the International Association of Computer Information Systems named him the International Computer Educator of the Year. 